\title{
Electroanalytical determination of gallic acid in red and white wine samples using cobalt oxide nanoparticles-modified carbon-paste electrodes.
}

CHIKERE, C.O., HOBBEN, E., FAISAL, N.H., KONG THOO LIN, P. and FERNANDEZ, C. 


\section{Electroanalytical determination of gallic acid in Red and White wine samples using Cobalt Oxide Nanoparticles-modified carbon- paste electrodes}

Chrys. O. CHIKEREa , Emma HOBBENa, Nadimul Haque FAISAL ${ }^{\text {b }}$, Paul KONGTHOO-LIN ${ }^{a}$, Carlos FERNANDEZ ${ }^{\text {a }}$

a. School of Pharmacy and Life Sciences, the Robert Gordon University, Aberdeen, AB10 7GJ, United Kingdom

b. School of Engineering, the Robert Gordon University, Aberdeen AB10 7GJ, United Kingdom

*Corresponding Author. Tel. +44 (0) 1224262559 E-mail: c.fernandez@,rgu.ac.uk

\section{Highlights}

- For the first time synthesised cobalt oxide nanoparticles modified CPE is used for the electrochemical determination of gallic acid

- Differential pulse voltammetry and cyclic voltammetry were used for the characterisation of the modified electrode and also for the determination of gallic acid

- The cobalt oxide nanoparticles modified electrode was used for Red and White wine analysis, producing a third peak current at increased GA concentration in Red wine. 


\title{
Electroanalytical determination of gallic acid in Red and White wine samples using Cobalt Oxide Nanoparticles-modified carbon- paste electrodes
}

\author{
Chrys. O. CHIKEREa , Emma HOBBENa, Nadimul Haque FAISAL ${ }^{\text {b }}$, Paul KONG- \\ THOO-LINa, Carlos FERNANDEZ ${ }^{\text {** }}$ \\ a. School of Pharmacy and Life Sciences, the Robert Gordon University, Aberdeen, AB10 7GJ, United \\ Kingdom \\ b. School of Engineering, the Robert Gordon University, Aberdeen AB10 7GJ, United Kingdom \\ *Corresponding Author.Tel.+44 (0) 1224262559 E-mail: c.fernandez@rgu.ac.uk
}

\begin{abstract}
Beverages like wines, have exhibited high level of antioxidant capacity, specifically from compounds like Gallic acid (GA) and their derivatives. GA has shown great importance in the food industry and pharmaceutical industry as a food additive, anti-tumour, anti-viral, and antimutagenic agent. Red and white wines from the USA and Australia were electrochemically analysed for GA, using Cobalt oxide nanoparticles modified carbon paste electrode (CoO-NPs$\mathrm{CPE})$. The electrochemical studies demonstrated an efficient GA $\left(10 \mathrm{mmol} \mathrm{L}^{-1}\right)$ oxidation, with enhanced peak currents from $302 \mu \mathrm{A}$ to about $405 \mu \mathrm{A}$ ( $25 \%$ increase). The limit of detection (LOD) of the modified electrode was $1.52 \times 10^{-4} \mathrm{mmol} \mathrm{L}^{-1}$ within the concentration range of 1 $\times 10^{-4}$ to $1 \times 10^{-3} \mathrm{mmol} \mathrm{L}^{-1}$. The CoO-NPs-CPE was successfully used, for the quantitative analysis of GA in red and white wine, showing average recoveries of $97 \%$ and $101 \%$ respectively. Hence our electrode can be applied for GA quantification in wine matrices.
\end{abstract}

Keywords: : Cobalt oxide nanoparticles, Carbon paste electrode, Phenolic acids, Gallic acid, Wine samples 


\section{Introduction}

Gallic acid (GA) also known as 3,4,5-trihydrobenzoic acid is a natural phenolic compound, which can be found in plants like tea, grapes, blueberries, walnuts, apples and herbs [1]. GA has been used widely in the food industry as a food additive and as an antiradical, antihistaminic, anti-mutagenic, anti-tumour and anti-inflammatory chemical compound in the pharmaceutical industry [2-5]. With these properties, GA is seen as an important compound in human diets. This is because it helps in reducing the risk of disease development, by preventing or slowing down molecular oxidation known as oxidative stress in the human body [6]. It should be noted that, oxidative stress has been linked to human diseases such as Alzheimer's disease, Parkinson's disease, cancer, cardiovascular diseases and diabetes [7,8].

With these important uses of GA in the food, drink and pharmaceutical industries, there has been a need for very good analytical methods for its determination in real samples. The analytical methods that have been traditionally used for the determination of GA are high performance liquid chromatography (HPLC) [9], flow injection analysis [10], spectrophotometry [11], and flow injection-chemiluminescence [12]. Although these techniques have shown high sensitivity, they have also needed very expensive equipment, skilled operators, elaborate procedures, and complicated sample preparations. However, electrochemical methods $[13,14]$ have shown advantages that include, high sensitivity, low cost, high selectivity, very short measurement time and are easy to use as compared to the other methods [15-17]. They also provide more information about the reaction mechanism of the compound being analysed [18-21].

Several carbon-based electrochemical sensors have been developed for the determination of GA in food matrices. These include modified glassy carbon electrode (GCE) [22,23], nanomaterials functionalized carbon-based composite electrodes [24], modifiedscreen-printed electrodes [1] and modified carbon paste electrodes (CPE) [25,26]. Among all 
the electrochemical methods and electrode modifications available, carbon paste electrodes modifications appear to be the technique of choice $[27,28]$. This is due to the low cost of modifying carbon paste electrodes, very low background current, flexibility, ease to effect modification, quick regenerative surface, wide potential window, and its good electrochemical sensing properties, like low ohmic resistance [29-31].

Carbon paste electrodes (CPEs) are a mixture of carbon (graphite) powder and pasting liquid or binder like paraffin oil. Different types of carbonaceous materials and modifiers have been used to develop CPE using different methods. These include carbon nanotubes, graphite, carbon nanofibers, polymers, and nanomaterials [32,33]. These modified carbon paste electrodes have been used as working electrodes in electrochemical experiments aimed at identifying, characterising and quantifying GA. Fayemi \& Adekunle, (2015) modified multiwalled carbon nanotubes doped with metal oxide nanoparticles (nickel oxide, zinc oxide and iron oxide nanoparticles), where they were used for the determination of dopamine. On the other hand $\mathrm{SiO}_{2}$ nanoparticles and $\mathrm{TiO}_{2}$ nanoparticles [35] respectively, have been used to modify carbon paste electrode, where they were used for the successful determination of GA in, tap water, orange juice and tea samples (black and green teas). However, there are no evidence of metal oxide nanoparticles modified carbon paste electrode that have used for the electrochemical determination of GA in red and white wine samples.

In this era of nanomaterials, different metal oxide nanoparticles have been used to modify CPE for the electrochemical determination of many organic compounds. Most recently $\mathrm{ZnO}$ nanoparticles and amorphous zirconium oxide nanoparticles modified $\mathrm{CPE}$ have been used for the determination of GA in wine samples [25,36]. With the inherent capacity of transition metals towards electrocatalysis of organic compounds, there was a need to explore other transition metal oxides for the electrochemical determination of GA in food samples. Cobalt oxide $\left(\mathrm{Co}_{3} \mathrm{O}_{4}\right)$ nanoparticle is a transition metal oxide nanoparticle that has been used 
in electrochemical sensor fabrication. Many different earth-abundant metal oxide nanoparticles materials for electrochemical determinations. Amongst these compounds, $\mathrm{Co}_{3} \mathrm{O}_{4}$ nanoparticles have attracted much interest because of their catalytic ability, large surface area, high activity and strong stability [38]. The cobalt oxide nanoparticles have been used in different fields as catalysts, energy storage units and electrochemical sensors [39,40]. Puangjan and Chaiyasith [26] produced a novel $\mathrm{Co}_{3} \mathrm{O}_{4}$ and $\mathrm{ZrO}_{2}$ nanoparticles nanocomposite with reduced graphene oxide on to a fluorine-doped electrode for the determination of GA. Their nanocomposite electrode was used for the simultaneous determination of GA, caffeic acid (CA) and protocatechuic acid (PA). $\mathrm{Co}_{3} \mathrm{O}_{4}$ nanoparticles acted as a composite with zirconia in the determination of GA, CA, and PA. However, the recorded properties of cobalt oxide nanoparticles alone, have not previously been explored for the development of electrochemical sensors for GA determination in wine matrices. Hence, for the first time this study was performed, to use the physicochemical properties of $\mathrm{Co}_{3} \mathrm{O}_{4}$ nanoparticles to produce a novel nanomaterial-based electrochemical sensor for fast, sensitive, cost-effective, and selective analysis of GA in wine samples.

\section{Experimental}

\subsection{Chemicals and reagents}

All chemicals and reagents were of analytical grade and were used as purchased with no further purification unless otherwise stated. Gallic acid (anhydrous), cobalt (II) nitrate hexahydrate $\left(\mathrm{Co}\left(\mathrm{NO}_{3}\right)_{2} \cdot 6 \mathrm{H}_{2} \mathrm{O}\right)$ (purity: $\left.\geq 98 \%\right)$ and sodium hydroxide pellets $(\mathrm{NaOH})$, Graphite powder and paraffin oil were purchased from Sigma Aldrich (London, UK). Potassium ferricyanide (purity: $\geq 99 \%$ ), potassium chloride $(\mathrm{KCl})$, disodium hydrogen orthophosphate $\left(\mathrm{N}_{2} \mathrm{k} \mathrm{PO}_{4}\right)$, sodium dihydrogen orthophosphate $\left(\mathrm{NaH}_{2} \mathrm{PO}_{4}\right)$ were from Merck (Darmstadt, Germany). Stock of buffers and gallic acid solutions were kept protected from light at $4{ }^{\circ} \mathrm{C}$. All aqueous 
solutions used in this study were made with doubly distilled water with a $18.2 \mathrm{M} \Omega . \mathrm{cm}$

102 resistance value. Wine samples were made from commercially available wines from a local store in the city of Aberdeen.

\subsection{Instrumentation and Apparatus}

Voltammetric measurements and all other electrochemical measurements were carried out using Ivium vertex One potentiostat-galvanostat with Ivium software (Eindhoven, Netherlands). A standard three-electrode cell set-up was used for all the studies, including the modified-CPE as the working electrode, a platinum wire electrode as the auxiliary electrode and an $\mathrm{Ag} / \mathrm{AgCl}$ (saturated $\mathrm{KCl}$ ) as a reference electrode. Meanwhile, all potentials recorded in the study were done in reference to the $\mathrm{Ag} / \mathrm{AgCl}$ reference electrode. The morphology of the electrode surface and elemental analysis were studied using scanning electron microscopy (SEM) and an energy dispersive x-ray analysis (EDXA) spectrum. The measurements were done with a Carl Zeiss variable pressure scanning electron microscope (Oberkochen, Germany), fitted with an Oxford Instrument and energy dispersive X-ray analysis system. The Fourier transform infrared (FTIR) spectrometer used for the chemical bonding analysis was a Thermo Scientific Nicolet iS50 FTIR Spectrometer (Waltham, MA, USA). The thermogravimetric analysis (TGA) measurement was carried out on a PerkinElmer STA 6000 instrument (Waltham, Massachusetts, USA) in an oxygen atmosphere. The size characterisation of the synthesised $\mathrm{Co}_{3} \mathrm{O}_{4}$ nanoparticles, was done by dynamic light scattering (DLS) using a Malvern Zetasizer Nano ZS (Malvern, UK). All pH measurements were done with a Fisher Scientific Mettler Toledo Benchtop pH meter (Loughborough, UK). Meanwhile, $\mathrm{pH}$ adjustments of buffer solutions were done with sodium hydroxide $\left(1 \times 10^{2} \mathrm{mmol} \mathrm{L}^{-1}\right)$ for $\mathrm{pH}$ increase or phosphoric acid $\left(10 \mathrm{mmol} \mathrm{L}^{-1}\right)$ to lower the $\mathrm{pH}$. HPLC analysis was carried out with a Shimadzu HPLC system consisting of LC-20AD prominence liquid chromatography, 
using a SIL-20A autosampler and an SPD-M20A diode array detector (Kyoto, Japan). The

columns used for the measurements were the $\mathrm{C}_{18}$ ODS Hypersil-Keystone LC -18 $(150 \times 4.6$

127

128

129

130

131

132

133

134

135

136

137

138

139

140

141

142

143

144

145

146

147

$\mathrm{mm}$ i.d., $3 \mathrm{~mm})$ in conjunction with a Supelguard LC $18(2 \mathrm{~cm} \times 2.1 \mathrm{~mm}$ i.d.) guard cartridge column. The software used for all the analysis was the Shimadzu LC solution software (Kyoto, Japan).

\subsection{Synthesis of Cobalt Oxide nanoparticles}

Cobalt oxide nanoparticles $\left(\mathrm{Co}_{3} \mathrm{O}_{4}\right)$ was synthesised by a co-precipitation method previously described [41]. Cobalt (II) nitrate hexahydrate $\left(\mathrm{Co}\left(\mathrm{NO}_{3}\right)_{2} \cdot 6 \mathrm{H}_{2} \mathrm{O}\right)(5.82 \mathrm{~g}$ in $20 \mathrm{ml} ; 1 \mathrm{M})$ and $\mathrm{NaOH}$ in a 1:2 $\mathrm{M}$ ratio (molar ratio), were dissolved in distilled water $(20 \mathrm{~mL})$, while stirring constantly. Using the molar ratio, $\mathrm{NaOH}$ solution $\left(2 \times 10^{3} \mathrm{mmol} \mathrm{L}^{-1}\right)$ was added dropwise to $\mathrm{Co}\left(\mathrm{NO}_{3}\right)_{2} \cdot 6 \mathrm{H}_{2} \mathrm{O}\left(1 \times 10^{3} \mathrm{mmol} \mathrm{L}^{-1}\right)$, under constant stirring for $2 \mathrm{hr}$ at room temperature $(\sim$ $25{ }^{\circ} \mathrm{C}$ ). The solution mixture was then left to settle overnight at room temperature. Cobalt hydroxide sludge was found to settle at the bottom of the flask the next day. Meanwhile, the excess solution on top of the sludge was carefully decanted and the precipitated sludge was then separated using a centrifuge (15000 RPM for 15 mins). The residue was then heated for 5 hrs at $80{ }^{\circ} \mathrm{C}$ to form a black colour compound ( $80 \%$ yield).

The cobalt oxide nanoparticles synthesised were characterised by measuring the particle sizes with a Zetasizer and other physical structures studied, using SEM, EDXA, and FTIR.

\subsection{Preparation of the modified Carbon Paste Electrodes}

Graphite powder and paraffin oil binder mixture ratio for the bare CPE were optimised for the best results. The bare CPE was prepared by thoroughly mixing and grinding in graphite powder and paraffin oil $(70: 30 ; \mathrm{w} / \mathrm{w})$ ratio into a homogenous paste using an agate mortar and pestle for $30 \mathrm{~min}$. The homogenous paste was then transferred into a solvent-resistant Teflon tube of 
$2.87 \mathrm{~mm}$ internal radius and smoothened on a weighing paper. The other end of the filled Teflon

149 tube was connected to copper wire to provide a connection. The modified CPE was prepared by mixing graphite powder, $\mathrm{Co}_{3} \mathrm{O}_{4}$ nanoparticles and paraffin oil in a 60:10:30 (w/w/w) ratio.

151 The mixture was thoroughly grounded with an agar mortar and pestle for about 30 mins and 152 then the paste was transferred into a Teflon tube.

\subsection{Preparation of wine samples}

154 The measurement of the GA content in the wine samples was carried out using differential 155 pulse voltammetry (DPV), by recording the voltammograms produced by spiked samples of the wine. Each wine sample $(1 \mathrm{~mL})$ was made up to $10 \mathrm{~mL}$ in a voltammetric cell with phosphate buffer solution (10 $\left.\mathrm{mmol} \mathrm{L}^{-1}, \mathrm{pH} 2.0\right)$. In all the samples, their $\mathrm{pH}$ was adjusted to 2.0 with phosphoric acid $\left(10 \mathrm{mmol} \mathrm{L}^{-1}\right)$. In measuring the spiked samples of the wine, aliquots amount of gallic acid solution $\left(\left(1 \mathrm{~mL}, 10 \mathrm{mmol} \mathrm{L}^{-1}\right)\right.$ were added to the wine sample, while stirring for 2 mins followed by the recording of the voltammogram.

\subsection{Electrochemical measurements}

The electrochemical oxidation of gallic acid on the surface of the cobalt oxide nanoparticlesmodified carbon paste electrode (CoO-NPs-CPE) was carried out using CV and DPV. The cyclic voltammograms were carried out in a potential scan range of 0.0 to $+1.5 \mathrm{~V}$ and a scan rate of $100 \mathrm{mVs}^{-1}$. For the differential pulse voltammetry, measurements were done at a potential scan range of 0.0 to $+1.5 \mathrm{~V}$, with a pulse amplitude of $0.08 \mathrm{~V}$ and a pulse period of $0.2 \mathrm{~s}$. All the electrochemical analysis of GA on the surface of all the carbon paste electrodes, were done in phosphate buffer $\left(1 \times 10^{2} \mathrm{mmol} \mathrm{L}^{-1}, \mathrm{pH} 2.0\right)$ at room temperature.

Electrochemical impedance spectroscopy (EIS) of the bare and modified CPE was carried out to ascertain the impedance changes between the bare and modified electrodes. The frequency 
range of $100 \mathrm{KHz}-0.1 \mathrm{~Hz}$ was used for the EIS measurement at a potential of $0.4 \mathrm{~V}$ in $1 \times 10^{2}$ mmol L-1 $\mathrm{KCl}$ containing $5 \mathrm{mmol} \mathrm{L}-1\left[\mathrm{Fe}(\mathrm{CN})_{6}\right]^{3-/ 4-}$ redox solution.

The synthesised $\mathrm{Co}_{3} \mathrm{O}_{4}$ nanoparticles were analysed with SEM, EDX, FTIR, and TGA. The

SEM and EDXA were used to study the morphology and elemental composition of the nanoparticles. Fig 1 shows the SEM images and EDXA analysis, with the morphology, microstructure, and the elemental composition of the $\mathrm{Co}_{3} \mathrm{O}_{4}$ nanoparticles (Fig 1(a)) and the

\section{Results and discussion}

\subsection{Characterisation of $\mathrm{Co}_{3} \mathrm{O}_{4}$ nanoparticles-modified CPE}

CoO-NP-CPE (Fig 1(b)). The SEM images show non-homogenous size distributions of cobalt oxide nanoparticles, ranging from $60 \mathrm{~nm}$ to $280 \mathrm{~nm}$ as demonstrated by the Dynamic Light Scattering (DLS) results (Fig. 1(d)). This is in line with Yang, Liu, Martens, \& Frost, (2010) who showed particles sizes of $100 \mathrm{~nm}$ to $600 \mathrm{~nm}$. The elemental composition (Fig 1(c)) of the nanosized cobalt oxide compound shows the proportional atomic ratio (3:4) of cobalt and oxygen. Meanwhile, the CoO-NP-CPE paste (Fig 1(b)), shows also a non-homogeneous morphology, with the milky coloured presence of the paraffin oil binder. The nanosized composition of the CoO-NP-CPE as shown in Fig 1(b) contributed to the peak current enhancement and provided better mass transport when used, as seen in later experiments.

Fig 1. (a) The SEM Image of Cobalt oxide nanoparticles showing the morphology of the nanoparticles with (Inset) $\mathrm{Co}_{3} \mathrm{O}_{4}$ in $100 \mathrm{~nm}$ (b) SEM Image of CoO-nano-CPE, with the paraffin holding the Cobalt oxide nanoparticles and graphite together (c) EDXA analysis of Cobalt oxide nanoparticles (d) Size distribution of cobalt oxide nanoparticles using a Zetasizer.

The FTIR characterisation of the cobalt oxide nanoparticles was carried out in the mid-infrared range (MIR) of 400 to $4000 \mathrm{~cm}^{-1}$ (Fig. S1), set in transmittance mode, with a resolution of 4 $\mathrm{cm}^{-1}$ and scanned 32 times. From the FTIR spectrum, the absorption peak at $558 \mathrm{~cm}^{-1}$ is assigned to the Co-O stretching vibration, as octahedrally coordinated by the $\mathrm{Co}^{3+}$ ions. 
Meanwhile, the $658 \mathrm{~cm}^{-1}$ absorption band is attributed to the bridging vibration in $\mathrm{Co}^{2+}$ ion,

which in this case is tetrahedrally coordinated [43]. The strong absorbance as seen at $1340 \mathrm{~cm}^{-1}$ could be attributed to traces of unreacted $\mathrm{Na}-\mathrm{OH}$. On the other hand, water absorbed by the $\mathrm{Co}_{3} \mathrm{O}_{4}$ nanoparticles is linked to the $3400-3600 \mathrm{~cm}^{-1}$ bands attributed to the $\mathrm{O}-\mathrm{H}$ stretching and bending [44].

The thermogravimetric analysis (TGA) of the cobalt oxide nanoparticles (Fig. S2) was carried to ascertain the thermal stability of the nanoparticles. The oxygen flow rate of the TGA was 20 $\mathrm{mL} \min ^{-1}$ and the rate of heating of the sample was $10{ }^{\circ} \mathrm{C} \min ^{-1}$ using $\alpha$-alumina crucibles, from room temperature to $900{ }^{\circ} \mathrm{C}$. From the analysis, the TGA profile showed three main stepdowns. The first step started with an initial weight loss up to $150{ }^{\circ} \mathrm{C}$ which could be mainly attributed to the evaporation of water molecules absorbed on the CoO-NP. The temperature then rises for the second step of weight loss from $210{ }^{\circ} \mathrm{C}$ to $500{ }^{\circ} \mathrm{C}$ which is attributed to the volatilisation and combustion of organic species with the formation of the pyrochlore phases [45]. The last weight loss step from $500{ }^{\circ} \mathrm{C}$ to $650{ }^{\circ} \mathrm{C}$ is attributed to the decomposition of the pyrochlore phases to the CoO-NPs pure phases. With no further significant weight loss up to $900{ }^{\circ} \mathrm{C}$ on the TGA curve, suggesting the formation of a decomposed cobalt oxide product.

The results of the characterisation confirm the synthesis of cobalt oxide nanoparticles which were used for the modification of the carbon paste electrode.

\subsection{Electrochemical characterisation of CoO-NPs-CPE}

The electrochemical determination of GA $\left(10 \mathrm{mmol} \mathrm{L}^{-1}, \mathrm{pH} 2.0\right)$ in phosphate buffer $\left(1 \times 10^{2}\right.$ mmol L-1) was carried out using bare CPE and the cobalt oxide nanoparticles-modified CPE (CoO-NPs-CPE). Using Cyclic voltammetry as shown in Fig 2(a), at a scan rate of $100 \mathrm{mVs}^{-1}$ and a scan potential range of 0 to $+1.5 \mathrm{~V}$ in the absence of GA; there was no anodic peak current. However, when GA (10 mmol L-1, $\mathrm{pH} 2.0)$ was measured using CPE and the CoO- 
NPs-CPE, there were noticeable anodic peak currents respectively at a peak potential of 0.61

V (Fig. 2(a)). The peak currents produced by CoO-NPs-CPE showed up to a $25 \%$ positive enhancement of the peak current produced by the CPE. This demonstrates the effect of the $\mathrm{Co}_{3} \mathrm{O}_{4}$ nanoparticles on the $\mathrm{CPE}$ electrode, as it increases the electroactive surface area of the electrode. The effect of the CoO-NPs on the CPE was also demonstrated in the measurement of $5 \mathrm{mmol} \mathrm{L}^{-1}\left[\mathrm{Fe}(\mathrm{CN})_{6}\right]^{3-/ 4-}$ redox solution (Fig.2(b)), where the modified electrode $(\mathrm{CoO}-$ NPs-CPE) shows an enhanced peak current relative to the peak current of the bare CPE.

Electrochemical impedance spectroscopy (EIS) serves as an effective method to monitor and understand the chemical changes that have occurred in the course of modifying the electrodes from $\mathrm{CPE}$ to $\mathrm{CoO}-\mathrm{NPs}-\mathrm{CPE}$. The EIS measurement was carried out in a $\left[\mathrm{Fe}(\mathrm{CN})_{6}\right]^{3-/ 4-}(5 \mathrm{mmol}$ $\mathrm{L}^{-1}$ ) redox solution and the Nyquist plot produced (Fig 2(c)). The Nyquist plot of the impedance spectra shows a semi-circular domain and smaller linearly inclined domain. The semi-circular portion at the high frequencies indicates the reaction had undergone an electron transfer limited process. Meanwhile, the diameter of the semi-circular portion provides us with the electrontransfer resistance $\left(\mathrm{R}_{\mathrm{ct}}\right)$. The Nyquist plot of the impedance of the bare CPE (black curve) (Fig 2(c)) exhibits an apparent interfacial electron-resistance $\left(\mathrm{R}_{\mathrm{ct}}\right)$. For the CoO-NPs-CPE the semicircular part shows a reduced diameter as compared to the bare CPE, depicting an increased and facilitated interfacial electron transfer. This shows that, the use of cobalt oxide nanoparticles to modify the CPE helps to decrease the electron transfer resistance, as compared to the bare CPE.

Fig 2. (a) Cyclic voltammetry of GA $\left(10 \mathrm{mmol} \mathrm{L}^{-1}\right)$ at the CoO-NPs-CPE and bare CPE in $1 \times 10^{2}$ mmol L-1 phosphate buffer of $\mathrm{pH} 2.0$ at a scan rate of $100 \mathrm{mVs}^{-1}$. (b) The cyclic voltammograms of 5 mmol L-1 $\left[\mathrm{Fe}(\mathrm{CN})_{6}\right]^{3-/ 4-}$ redox solution, using bare $\mathrm{CPE}$ and CoO-NPs-CPE, (c) Nyquist plot showing the EIS measurements of $\left[\mathrm{Fe}(\mathrm{CN})_{6}\right]^{3-/ 4-}\left(5 \mathrm{mmol} \mathrm{L}^{-1}\right)$ using the bare $\mathrm{CPE}$ and $\mathrm{CoO}-\mathrm{NPs}-\mathrm{CPE}$ (inset) The equivalent circuit used for the calculation 
The effective reactive surface area of the modified electrode was also studied, using the electrodes to determine $\mathrm{KCl}\left(1 \times 10^{2} \mathrm{mmol} \mathrm{L}^{-1}\right)$ solution in $\left[\mathrm{Fe}(\mathrm{CN})_{6}\right]^{3-/ 4-}\left(1 \mathrm{mmol} \mathrm{L}^{-1}\right)$ using $\mathrm{CV}$ at different scan rates $\left(100,200,250,300,350,400,450 \mathrm{mVs}^{-1}\right)$. From the voltammograms produced (Fig. S3(a)) the plots of peak currents $\left(I_{\mathrm{p}}\right)$ vs square root of scan rate $\left(v^{1 / 2}\right)($ Fig. S3(b)) was generated and used for the determination of reactive surface area, using the RandlesŚev $\square$ ik equation thus: unmodified electrodes was studied using CV. GA (10 mmol L-1, $\mathrm{pH} 2.0)$ was oxidised on the faces of three different electrodes, in a phosphate buffer $\left(10 \mathrm{mmol} \mathrm{L}^{-1}\right)$, at a scan rate of 100 $\mathrm{mVs}^{1}$. As shown in Fig. 3, bare CPE, bulk $\mathrm{Co}_{3} \mathrm{O}_{4}$ (bulk-CoO-CPE) and CoO-NPs-CPE

267 produced anodic peak currents in the scan potential range of 0 to $+1.5 \mathrm{~V}$ at room temperature.

268 Meanwhile, there was no peak seen when the electrodes were used on phosphate buffer alone,

Where $I_{\mathrm{pa}}$ is the anodic peak current, $n$ is the number electrons involved in the transfer, in the course of the redox reaction, $A$ is the effective surface area of the electrode, $D$ is the diffusion coefficient for $\mathrm{K}_{3}\left[\mathrm{Fe}(\mathrm{CN})_{6}\right]$ which is $7.6 \times 10^{-6} \mathrm{~cm}^{2} \mathrm{~s}^{-1}, v$ is the scan rate and $C$ is the concentration of $\mathrm{K}_{3}\left[\mathrm{Fe}(\mathrm{CN})_{6}\right]$. From the plot of $I_{\mathrm{p}} \mathrm{vs} v^{1 / 2}$ the anodic peak currents produced the linear regression equation of $I_{\mathrm{p}}=64.827 v^{1 / 2}+176.92, \mathrm{R}^{2}=0.9983$ and the cathodic peak currents gave $I_{\mathrm{p}}=-97.399 v^{1 / 2}-492.72, \mathrm{R}^{2}=0.9997$. Using the Randles-Śev $\square$ ik equation, the effective surface area was calculated to be $0.088 \mathrm{~cm}^{2}$ for CPE and $0.321 \mathrm{~cm}^{2}$ for the CoO-NPsCPE. From the calculation, it can be seen that the effective surface area of the CPE was less than that of the CoO-NPs-CPE. This shows that, the cobalt oxide nanoparticles served as an effective modifier that increased the surface area of the electrode.

\subsection{Electrochemical behaviour of gallic acid on the CPE}

The electrochemical behaviour of the GA on the surface of the modified and 
through the same potential range of 0.0 to $+1.5 \mathrm{~V}$. The voltammograms (Fig.3) shows the

270 anodic peak currents produced by all the electrodes in the presence of GA, as two oxidation

271 peaks. The first oxidation peak is much more prominent than the second and is the peak used

272 for the determination of GA.

The oxidation peak current of GA when using bare CPE, bulk-CoO-CPE and CoONPs-CPE produced peak current at peak potentials of $0.6-0.67 \mathrm{~V}$ as can be seen in Fig 3. From these voltammetric results, CoO-NPs-CPE showed the highest oxidation peak current as compared to the other electrodes. This demonstrates the effect of the cobalt oxide nanoparticles in the CPE modification and the GA oxidation, where the peak current was enhanced.

Fig 3. Cyclic voltammograms of $10 \mathrm{mmol} \mathrm{L}^{-1} \mathrm{GA}$ at $\mathrm{Co}_{3} \mathrm{O}_{4}$ nanoparticles-modified CPE, bulk $\mathrm{Co}_{3} \mathrm{O}_{4}$ nanoparticles-modified CPE and bare CPE in $1 \times 10^{2} \mathrm{mmol} \mathrm{L}^{-1}$ phosphate buffer of $\mathrm{pH} 2.0$ at a scan rate of $100 \mathrm{mVs}^{-1}$

On the other hand, the bulk CoO-CPE that was used for the modification of CPE, produced a negative effect on GA oxidation. The peak current produced by the bulk CoO-CPE was less than those of the bare $\mathrm{CPE}$ and CoO-NPs-CPE. Showing peak currents of the electrodes as CoO-NPs-CPE $>$ bare $\mathrm{CPE}>$ bulk $\mathrm{CoO}-\mathrm{CPE}$. This might be as a result of reduced electroactive surface area attributed to the bulk cobalt oxide, as compared to the cobalt oxide nanoparticles in the carbon paste electrode. This is because the increased electroactive surface area of metal oxide nanoparticles tend to enhance the peak currents of the modified electrode $[22,36,46]$.

The enhanced peak current of the oxidised GA, when CoO-NPs-CPE was used may be due to the higher surface area and the adsorptive capacity of the modified electrode surface. The more GA is adsorbed on the surface of the modified electrode the higher is the accumulation efficiency and increase in the surface concentration. However, it can be observed from the voltammograms shown in Fig 3 that, the peak potential at the determination of GA on CoO-NPs-CPE shows a little positive shift of $0.01 \mathrm{~V}$ as compared to that of the bare CPE. This 
shows that, the cobalt oxide nanoparticles did not catalyse the oxidation of GA, but enhanced the peak current generated by the oxidation reaction. Had there been any catalysis, the peak potential would have had a negative shift to the bare CPE. The reduction of peak potential

\subsection{Effect of pH on Gallic Acid Oxidation}

The effect of the $\mathrm{pH}$ on the electroanalytical performance of the CoO-NPs-CPE on the detection of GA, was studied using CV and the voltammograms recorded as seen in Fig. S5(a) and S5(b). The modified electrode was used to measure GA $\left(1 \mathrm{mmol} \mathrm{L}^{-1}\right)$ in phosphate buffer $\left(1 \times 10^{2} \mathrm{mmol} \mathrm{L}^{-1}\right)$ at $\mathrm{pH}$ values of $2.0,4.0,6.0,8.0$ and 10 , at a scan rate of $100 \mathrm{mVs}^{-1}$. From the literature [22] it can be seen that GA oxidation is influenced by a protonation reaction (Fig. 
S5), thus suggesting its oxidation is influenced by the $\mathrm{pH}$ condition of the buffer. From the voltammograms recorded in Fig. S5(a) and S5(b), the anodic peak currents of GA decreased with the increasing $\mathrm{pH}$ values and a negative shift of the anodic peak potentials. The bestresolved peak current from the voltammograms, was the peak current produced at $\mathrm{pH} 2.0$. It could be deduced from the results that the oxidation procedure of gallic acid is related to $\mathrm{H}^{+}$ ions of the solution, as seen in Fig. S4. The results show that the GA oxidation peak currents decrease linearly with the increase in $\mathrm{pH}$ value of the solution. This produce a non-linear equation of $I_{\mathrm{p}}=-2107 \mathrm{pH}+32.755$ and $\mathrm{R}^{2}=0.9203$ (Fig. S5(d)). Meanwhile, the plot of peak potential $\left(\mathrm{E}_{\mathrm{p}}\right) \mathrm{vs} \mathrm{pH}$ showed a good linear relationship in the $\mathrm{pH}$ range of 2.0 to 8.0 , that produced a linear regression equation of $E_{\mathrm{p}}=-0.058 \mathrm{pH}+0.655$ and $\mathrm{R}^{2}=0.9938$. From the linear regression equation, the slope $E_{\mathrm{p}} / \mathrm{pH}$ of the regression line is $58 \mathrm{mV} / \mathrm{pH}$. This is almost equivalent to the Nernstian value of $59 \mathrm{mV} / \mathrm{pH}$ at room temperature, for an equal number of protons and electrons transfer reactions. The oxidation reaction of GA on the surface of CoONPs-CPE is two electrons and two protons process (Fig. S4). With the positive shift of the oxidation peak potential as the $\mathrm{pH}$ decreases, it indicates that, GA needs higher potential for its oxidation at low $\mathrm{pH}$ values. However, based on the peak currents produced, $\mathrm{pH} 2.0$ was used for subsequent experiments, which is in line with other works in the literature $[22,36,47]$.

Just looking at the colour changes observed (Fig. S6) with GA in different pH, suggests an influence of $\mathrm{pH}$ in GA oxidation. UV spectrophotometer was used to measure the colour changes of the different GA acid solutions at different $\mathrm{pHs}$ at $280 \mathrm{~nm}$ and the absorbance recorded (Table 1). From the absorbance results, the higher $\mathrm{pH}$ solutions show an extensive change in colour which can be attributed to the reduction of GA caused by its exposure to light. This phenomenon just confirms the effect of $\mathrm{pH}$ in GA oxidation. Hence all GA solutions were protected from light by wrapping the glassware with aluminium foil and refrigerated at $4{ }^{\circ} \mathrm{C}$.

Table 1. The absorbance values of GA $\left(1 \mathrm{mmol} \mathrm{L}^{-1}\right)$ at different $\mathrm{pH}$ at the wavelength of $280 \mathrm{~nm}$ 


\subsection{Effect of scan rate on Gallic Acid Oxidation}

The influence of the scan rate on the electrooxidation of GA on the surface of the CoO-

NPs-CPE was also studied using CV. GA $\left(1 \mathrm{mmol} \mathrm{L}^{-1}\right)$ in phosphate buffer $\left(1 \times 10^{2} \mathrm{mmol} \mathrm{L}^{-}\right.$

$3461, \mathrm{pH} 2.0$ ) was measured, within the scan rate range of $25-1000 \mathrm{mVs}^{-1}$, at room temperature

347 (Fig. S7(a)). From the results of the scan rate, it can be seen that the oxidation peak currents

$348\left(I_{\mathrm{p}}\right)$ of GA increased linearly with the scan rate $(v)$ within the range of $50-400 \mathrm{mVs}^{-1}$. This is

\subsection{Effect of CoO-NPs concentration on the CPE mixture}

The effect of the concentration of cobalt oxide nanoparticles (CoO-NPs) in preparing the modified-carbon paste electrode was studied using CV. Cobalt oxide nanoparticles $(0.5 \mathrm{~g}$, $0.1 \mathrm{~g}, 0.15 \mathrm{~g}$ and $0.2 \mathrm{~g}$ ) were weighed and mixed with graphite powder of appropriate ratio (Making up the graphite to $70 \%$ of the CPE and Paraffin 30\%; w/w). The modified electrodes were then used for the electrochemical determination of GA $\left(10 \mathrm{mmol} \mathrm{L}^{1}\right)$ in phosphate buffer solution $\left(1 \times 10^{2} \mathrm{mmol} \mathrm{L}^{-1}, \mathrm{pH} 2.0\right)$ and a scan rate of $100 \mathrm{mVs}^{-1}$. From the results (Fig. S8), the CoO-NPs-CPE that had 10\% cobalt oxide nanoparticles showed the highest current and most resolved peak. Therefore, the $10 \%$ cobalt oxide nanoparticles-modified CPE was subsequently used for further experiments and electrochemical determinations of GA.

\subsection{Calibration curve and the limit of detection of GA determination}



curve and the limit of electrochemical detection (oxidation) of GA at the surface of the CoO-

NPs-CPE. The DPV was recorded at a potential range of 0 to $+1.5 \mathrm{~V}$, the scan rate of $100 \mathrm{mVs}^{-}$

368 , pulse amplitude of $80 \mathrm{mV}$ and a pulse period of $0.2 \mathrm{~s}$. Using the optimised conditions 369 voltammograms were recorded from the oxidation of increasing concentrations of GA in phosphate buffer $\left(1 \times 10^{2} \mathrm{mmol} \mathrm{L}^{-1}, \mathrm{pH} 2.0\right)$ on the surface of the CoO-NPs-CPE (Fig. 4). The recorded results were then used for the determination of the calibration curve and the limit of detection (LOD) of the modified electrode.

From the results in Fig. 4, it is observed that the anodic peak currents changed linearly with the increasing GA concentration from the concentration range of $1 \times 10^{-4}$ to $1 \times 10^{-2} \mathrm{mmol}$ $\mathrm{L}^{-1}$. However, the linearity of the increasing peak current relative to the increase GA concentration was specifically between $1 \times 10^{-4}$ to $1 \times 10^{-3} \mathrm{mmol} \mathrm{L}^{-1}$, within the examined concentration range of $1 \times 10^{-4}$ to $1 \times 10^{-2}$. DPV produced voltammograms of GA with two peaks at peak potentials of $0.55 \mathrm{~V}$ and $0.9 \mathrm{~V}$, respectively. The peak potential showed a slight positive shift with increasing concentration of gallic acid, as can be seen in Fig 4 (a). The corresponding analytical calibration curve, as shown in Fig 4 (a) inset shows a linear relationship between the peak current $\left(I_{\mathrm{p}}\right)$ and the gallic acid concentration as seen in Fig 4 (a)

382 Fig 4. (a) Differential voltammograms of various concentrations of GA at CoO-nano-CPE in a $1 \mathrm{x}$ $38310^{-2} \mathrm{mmol} \mathrm{L}^{-1}$ phosphate buffer at $\mathrm{pH} 2.0$ at scan rate of $100 \mathrm{mVs}^{-1}$, with voltammograms (a-j) 384 corresponds to the following concentrations a) Blank PBS, b) $1 \times 10^{-4} \mathrm{mmol} \mathrm{L}^{-1}$, c) $2.5 \times 10^{-4} \mathrm{mmol} \mathrm{L}^{-}$ $385{ }^{1}$, d) $5 \times 10^{-4} \mathrm{mmol} \mathrm{L}^{-1}$, e) $7.5 \times 10^{-4} \mathrm{mmol} \mathrm{L}^{-1}$, f) $1 \times 10^{-3} \mathrm{mmol} \mathrm{L}^{-1}$, g) $2.5 \times 10^{-3} \mathrm{mmol} \mathrm{L}^{-1}$, h) $5 \times 10^{-3}$ $386 \mathrm{mmol} \mathrm{L}-1$, i) $7.5 \times 10^{-3} \mathrm{mmol} \mathrm{L}^{-1}$, j) $1 \times 10^{-2} \mathrm{mmol} \mathrm{L}^{-1}$ (inset) Plot of concentration of GA against peak currents. (b) The plot of the Peak Current $\left(\mathrm{I}_{\mathrm{p}}\right)$ against the concentration of GA, showing the effect of concentration on the electrochemical behaviour of increasing GA concentration, using CoO-nano-CPE at a scan rate of $100 \mathrm{mVs}^{-1}$

The first and major peaks from the DPV voltammograms produced from the different GA concentrations were used to create the calibration graph (Fig. 4(a) inset and Fig. 4(b)). The 
linear relationship is depicted in the linear regression equation, which is also the calibration curve as $\mathrm{I}_{\mathrm{p}}=11285.86 \mathrm{C}-0.07936\left(I_{\mathrm{P}}: \mu \mathrm{A}, C: \mathrm{mmol} \mathrm{L}^{-1}\right)$ and $R^{2}=0.9934$ from $1 \times 10^{-4} \mathrm{mmol}$ $\mathrm{L}^{-1}$ to $1 \times 10^{-2} \mathrm{mmol} \mathrm{L}^{-1}$ as seen Fig. 4 (b). Meanwhile, the limit of detection (LOD) defined as $\left(3 \times S t d_{\text {Blank }}\right) / m$ where $S t d_{\text {Blank }}$ is the standard deviation of the blank and $m$ is the slope; was found to be $1.52 \times 10^{-4} \mathrm{mmol} \mathrm{L}^{-1}(\mathrm{~S} / \mathrm{N}=3)$ and concentration range $1 \times 10^{-4} \mathrm{mmol} \mathrm{L}^{-1}$ to $1 \mathrm{X}$ $10^{-2} \mathrm{mmol} \mathrm{L}^{-1}$. The CoO-NPs-CPE showed a relatively wide linear dynamic range and the low limit of detection was comparable to others in the literature, where the limit of detections are between the range of $2.09 \times 10^{-6}$ to $1.5 \times 10^{-9} \mathrm{mmol} \mathrm{L}^{-1}[22,25,26,48]$. This is based on the fact that, the maximum permitted GA concentration in the EU and North America antioxidant limit guidelines is $1.2 \times 10^{2} \mathrm{mmol} \mathrm{L}^{-1}$ to $6.0 \times 10^{3} \mathrm{mmol} \mathrm{L}^{-1}$. The LOD from this electrode is below this limit, hence would be suitable for use in GA determination of GA concentration even at high concentrations.

Table 2. Metal Oxide Nanoparticles (MO-NPs) and Metal Nanoparticles composites in different electrochemical sensor systems for the determination of Gallic acid.

\subsection{Reproducibility and repeatability of the method}

412 Furthermore, the repeatability of the method was studied, by taking six independent 413 measurements of GA $\left(5 \times 10^{-1} \mathrm{mmol} \mathrm{L}^{-1}\right)$ in phosphate buffer $\left(1 \times 10^{2} \mathrm{mmol} \mathrm{L}^{-1}, \mathrm{pH} 2.0\right)$ with 414 a CoO-NPs-CPE. From the result of the measurement (Fig. S9(b)), the relative standard 415 deviation of the voltammograms produced was $0.66 \%$, showing a very good repeatability. 


\subsection{Stability of the modified electrode}

417 The long-term storage stability of the modified electrode (CoO-NPs-CPE) was studied by 418 keeping the electrode at room temperature, then used twice to detect GA $\left(5 \times 10^{-1} \mathrm{mmol} \mathrm{L}^{-1}\right)$ 419 after 15 and 30 days, respectively using DPV. The recorded voltammograms for the first day, $42015^{\text {th }}$ day and $30^{\text {th }}$ day showed peak currents with RSD of $6.32 \%$ (Fig. S10), which demonstrated a good stability.

\subsection{Interference study}

The selectivity of the CoO-NPs-CPE was studied by determination of GA $\left(10 \mathrm{mmol} \mathrm{L}^{-1}\right)$, using

DPV conducting interference experiments in the presence of different metals ions $\left(\mathrm{K}^{+}, \mathrm{Cl}^{-}, \mathrm{Na}^{+}\right.$,

$\mathrm{Fe}^{3+}$ ) and other organic (antioxidant) compounds (ascorbic acid and quercetin). The use of those cations and organic compounds was because of their potential properties to complex or interfere with the electrochemical determination gallic acid respectively [51]. The results in

Fig. S11, showed RSD values of less than 5\%, suggesting the ions and the organic compound did not interfere with the determination of GA.

The modified carbon paste electrode was used for the determination of GA content in red and white wine. The presence of GA in red and white wine samples have previously been analysed by electrochemical determination and HPLC analysis [22,50]. The wine (Australia and USA) samples were diluted with phosphate buffer $\left(10 \mathrm{mmol} \mathrm{L}^{-1}\right)$ and the $\mathrm{pH}$ adjusted to 2.0 with 436 phosphoric acid $\left(1 \times 10^{2} \mathrm{mmol} \mathrm{L}^{-1}\right)$. The wine samples were then spiked with standard solutions of GA to obtain a GA range from $0-2.3 \mathrm{mmol} \mathrm{L}^{-1}$ followed by the recording of their corresponding DPV voltammograms Table 3, (Fig. S12(a) and Fig. S12(b)). The results 
showed that with CoO-NPs-CPE exhibited anodic peaks in the absence of GA. This suggests

440 that the cobalt oxide modified CPE electrode detected GA or showed an antioxidant capacity 441 in these wine samples (Fig. S12). The anodic peak current produced by the wine sample is 442 generally attributed to the total antioxidant capacity of the sample as described by Kilmartin et 443 al., (2001), Makhotkina and Kilmartin, (2009) and Lopez-Velez et al., (2003) [52-54]. Hence, 444 the use of the standard addition of GA to confirm the presence of GA in the wine sample. On 445 the other hand the confirmation of the presence of GA in the wine samples was carried out 446 using HPLC (Fig S14) and the results were in line with Ragusa et al., (2019); where they found 447 GA in Negroamaro and Primitivo red wines from Salento.

448 Table 3. Results of the analysis of GA in spiked Red Wine and White Wine

449 Furthermore, in the course of the determination of GA in the red wine sample there was an 450 unusual observation. As the standard solution of GA, that was being used for the spiking was increased, there was a third peak observed in the voltammograms (Fig. S13). In the 452 determination of GA in the red wine using CoO-NPs-CPE, the normal first and second peaks 453 of GA were noticed at peak potentials of $0.59 \mathrm{~V}$ and $1.02 \mathrm{~V}$, while, the third unusual peak is 454 seen at a peak potential of $0.76 \mathrm{~V}$. This third peak could be attributed to the activation of another 455 compound in the red wine as the GA concentration increases in the red wine sample.

\section{Conclusions}

457 In this work a novel $\mathrm{Co}_{3} \mathrm{O}_{4}$ nanoparticles-modified carbon paste electrode was successfully 458 prepared and used for the electrochemical determination of GA in phosphate buffer $\left(1 \times 10^{2}\right.$ 459 mmol L-1, pH 2.0) using CV and DPV. The CoO-NPs-CPE showed excellent activity on GA 460 oxidation and an enhancement in peak current of $25 \%$ as compared to the bare CPE. The 461 modified carbon paste electrode demonstrated good stability, reproducibility, and repeatability.

462 The selectivity of the modified electrode was demonstrated by using the electrode to determine 
$463 \mathrm{GA}$ in the presence of some interferant foreign species, like $\mathrm{K}^{+}, \mathrm{Cl}^{-}, \mathrm{Na}^{+}, \mathrm{Fe}^{3+}$, ascorbic acid 464 and quercetin. The characteristics of the modified electrode led to its use in the determination 465 of GA in red and white wine. With the low cost and ease of fabrication, the CoO-NPs-CPE 466 would be a suitable sensor for the determination of other phenolic compounds in food matrices.

\section{Acknowledgement}

468 The authors would want to acknowledge the work done by the research and teaching laboratory 469 staff of the School of Pharmacy and Life Sciences of the Robert Gordon University.

\section{Conflict of interest}

Dr. Chrys. O. Chikere declares that he has no conflict of interest. Ms. Emma Hobben declares that she has no conflict of interest. Dr. Nadimul H Faisal declares that he has no conflict of interest. Professor Paul Kong-Thoo-Lin declares that he has no conflict of interest. Dr. Carlos

Fernandez declares that he has no conflict of interest.

\section{Appendix A. Supplementary data}

\section{Reference}

477 [1] N. Raja, T. Kokulnathan, S.M. Chen, W.C. Liao, T. Sakthi Priya, Amperometric detection of gallic acid based on electrochemically activated screen printed carbon electrode, Int. J. Electrochem. Sci. 12 (2017) 4620-4629. https://doi.org/10.20964/2017.06.22.

[2] Y.C. Chia, R. Rajbanshi, C. Calhoun, R.H. Chiu, Anti-Neoplastic effects of gallic acid, a major component of toona sinensis leaf extract, on oral squamous carcinoma cells, Molecules. 15 (2010) 8377-8389. https://doi.org/10.3390/molecules15118377.

484 [3] C. Dalla Pellegrina, G. Padovani, F. Mainente, G. Zoccatelli, G. Bissoli, S. Mosconi, 
G. Veneri, A. Peruffo, G. Andrighetto, C. Rizzi, R. Chignola, Anti-tumour potential of a gallic acid-containing phenolic fraction from Oenothera biennis, Cancer Lett. 226 (2005) 17-25. https://doi.org/10.1016/j.canlet.2004.11.033. 488

B. Bajpai, S. Patil, A new approach to microbial production of gallic acid., Braz. J. Microbiol. 39 (2008) 708-11. https://doi.org/10.1590/S1517-838220080004000021.

[5] J. Jayamani, G. Shanmugam, Gallic acid, one of the components in many plant tissues, is a potential inhibitor for insulin amyloid fibril formation, Eur. J. Med. Chem. 85 (2014) 352-358. https://doi.org/10.1016/j.ejmech.2014.07.111.

I. Pinchuk, H. Shoval, Y. Dotan, D. Lichtenberg, Evaluation of antioxidants: Scope, limitations and relevance of assays, Chem. Phys. Lipids. 165 (2012) 638-647. https://doi.org/10.1016/j.chemphyslip.2012.05.003.

R. Nowak, M. Olech, N. Nowacka, Plant Polyphenols as Chemopreventive Agents, Polyphenols Hum. Heal. Dis. 2 (2013) 1289-1307. https://doi.org/10.1016/B978-0-12$398456-2.00086-4$.

A.A. Zanwar, S.L. Badole, P.S. Shende, M. V. Hegde, S.L. Bodhankar, Role of Gallic Acid in Cardiovascular Disorders, Elsevier Inc., 2013. https://doi.org/10.1016/B978-012-398456-2.00080-3.

[9] M. Tasioula-Margari, E. Tsabolatidou, Extraction, Separation, and Identification of Phenolic Compounds in Virgin Olive Oil by HPLC-DAD and HPLC-MS, Antioxidants. 4 (2015) 548-562. https://doi.org/10.3390/antiox4030548.

[10] W. Phakthong, B. Liawruangrath, S. Liawruangrath, Determination of gallic acid with rhodanine by reverse flow injection analysis using simplex optimization, Talanta. 130 (2014) 577-584. https://doi.org/10.1016/j.talanta.2014.06.024. 
508 [11] Z. Chen, R. Bertin, G. Froldi, EC50 estimation of antioxidant activity in DPPH* assay

[13] V. Andrei, E. Sharpe, A. Vasilescu, S. Andreescu, A single use electrochemical sensor

[12] S. Parveen, M.S. Aslam, L. Hu, G. Xu, Electrogenerated chemiluminescence protocols and applications, Springer Berlin Heidelberg, 2013. based on biomimetic nanoceria for the detection of wine antioxidants, Talanta. 156157 (2016) 112-118. https://doi.org/10.1016/j.talanta.2016.04.067.

[14] Madhusudhana, G. Manasa, A.K. Bhakta, Z. Mekhalif, R.J. Mascarenhas, Bismuthnanoparticles decorated multi-wall-carbon-nanotubes cast-coated on carbon paste electrode; an electrochemical sensor for sensitive determination of Gallic Acid at neutral pH, Mater. Sci. Energy Technol. 3 (2020) 174-182. https://doi.org/10.1016/j.mset.2019.10.001.

[15] H. Karimi-Maleh, F. Karimi, Y. Orooji, G. Mansouri, A. Razmjou, A. Aygun, F. Sen, A new nickel-based co-crystal complex electrocatalyst amplified by $\mathrm{NiO}$ dope $\mathrm{Pt}$ nanostructure hybrid; a highly sensitive approach for determination of cysteamine in the presence of serotonin, Sci. Rep. 10 (2020) 1-13. https://doi.org/10.1038/ s41598-020-68663-2.

[16] H. Karimi-Maleh, F. Karimi, M. Alizadeh, A.L. Sanati, Electrochemical Sensors, a Bright Future in the Fabrication of Portable Kits in Analytical Systems, Chem. Rec. (2020). https://doi.org/10.1002/tcr.201900092.

[17] Z. Shamsadin-Azad, M.A. Taher, S. Cheraghi, H. Karimi-Maleh, A nanostructure voltammetric platform amplified with ionic liquid for determination of tertbutylhydroxyanisole in the presence kojic acid, J. Food Meas. Charact. 13 (2019) 
1781-1787. https://doi.org/10.1007/s11694-019-00096-6.

533

534

535

536

537

538

539

540

541

542

543

544

545

546

547

548

549

550

551

552

553

554

555

[18] J. Ostojić, S. Herenda, Z. Bešić, M. Miloš, B. Galić, Advantages of an electrochemical method compared to the spectrophotometric kinetic study of peroxidase inhibition by boroxine derivative, Molecules. 22 (2017).

https://doi.org/10.3390/molecules22071120.

[19] D. Galato, K. Ckless, M.F. Susin, C. Giacomelli, R.M. Ribeiro-do-Valle, a Spinelli, Antioxidant capacity of phenolic and related compounds: correlation among electrochemical, visible spectroscopy methods and structure-antioxidant activity., Redox Rep. 6 (2001) 243-50. https://doi.org/10.1179/135100001101536391.

[20] M.J. Rebelo, R. Rego, M. Ferreira, M.C. Oliveira, Comparative study of the antioxidant capacity and polyphenol content of Douro wines by chemical and electrochemical methods, Food Chem. 141 (2013) 566-573. https://doi.org/10.1016/j.foodchem.2013.02.120.

[21] J. Hoyos-Arbeláez, L. Blandón-Naranjo, M. Vázquez, J. Contreras-Calderón, Antioxidant capacity of mango fruit (Mangifera indica). An electrochemical study as an approach to the spectrophotometric methods, Food Chem. 266 (2018) 435-440. https://doi.org/10.1016/j.foodchem.2018.06.044.

[22] C.O. Chikere, N.H. Faisal, P. Kong Thoo Lin, C. Fernandez, The synergistic effect between graphene oxide nanocolloids and silicon dioxide nanoparticles for gallic acid sensing, J. Solid State Electrochem. 23 (2019) 1795-1809. https://doi.org/10.1007/s10008-019-04267-9.

[23] Y. Gao, L. Wang, Y. Zhang, L. Zou, G. Li, B. Ye, Highly sensitive determination of gallic acid based on a Pt nanoparticle decorated polyelectrolyte-functionalized graphene modified electrode, Anal. Methods. 8 (2016) 8474-8482. 
https://doi.org/10.1039/c6ay02583h.

[24] C. Xiong, Y. Wang, H. Qu, L. Zhang, L. Qiu, W. Chen, F. Yan, L. Zheng, Highly sensitive detection of gallic acid based on organic electrochemical transistors with poly(diallyldimethylammonium chloride) and carbon nanomaterials nanocomposites functionalized gate electrodes, Sensors Actuators, B Chem. 246 (2017) 235-242. https://doi.org/10.1016/j.snb.2017.02.025.

[25] C. Chikere, N.H. Faisal, P.K.T. Lin, C. Fernandez, Zinc oxide nanoparticles modifiedcarbon paste electrode used for the electrochemical determination of Gallic acid, J. Phys. Conf. Ser. 1310 (2019) 012008. https://doi.org/10.1088/1742$6596 / 1310 / 1 / 012008$.

[26] A. Puangjan, S. Chaiyasith, An efficient $\mathrm{ZrO} 2 / \mathrm{Co} 3 \mathrm{O} 4 /$ reduced graphene oxide nanocomposite electrochemical sensor for simultaneous determination of gallic acid, caffeic acid and protocatechuic acid natural antioxidants, Electrochim. Acta. 211 (2016) 273-288. https://doi.org/10.1016/j.electacta.2016.04.185.

[27] H. Karimi-Maleh, M. Sheikhshoaie, I. Sheikhshoaie, M. Ranjbar, J. Alizadeh, N.W. Maxakato, A. Abbaspourrad, A novel electrochemical epinine sensor using amplified $\mathrm{CuO}$ nanoparticles and a: $\mathrm{N}$-hexyl-3-methylimidazolium hexafluorophosphate electrode, New J. Chem. 43 (2019) 2362-2367. https://

[28] M. Miraki, H. Karimi-Maleh, M.A. Taher, S. Cheraghi, F. Karimi, S. Agarwal, V.K. Gupta, Voltammetric amplified platform based on ionic liquid/NiO nanocomposite for determination of benserazide and levodopa, J. Mol. Liq. 278 (2019) 672-676. https:// doi.org/10.1016/j.molliq.2019.01.081.

[29] F. Tahernejad-Javazmi, M. Shabani-Nooshabadi, H. Karimi-Maleh, 3D reduced graphene oxide/FeNi3-ionic liquid nanocomposite modified sensor; an electrical 
synergic effect for development of tert-butylhydroquinone and folic acid sensor, Compos. Part B Eng. 172 (2019) 666-670. https://doi.org/10.1016/j.compositesb.2019.05.065.

[30] H. Karimi-Maleh, C.T. Fakude, N. Mabuba, G.M. Peleyeju, O.A. Arotiba, The determination of 2-phenylphenol in the presence of 4-chlorophenol using nano$\mathrm{Fe} 3 \mathrm{O} 4 /$ ionic liquid paste electrode as an electrochemical sensor, J. Colloid Interface Sci. 554 (2019) 603-610. https://doi.org/10.1016/j.jcis.2019.07.047.

[31] H. Karimi-Maleh, O.A. Arotiba, Simultaneous determination of cholesterol, ascorbic 588 acid and uric acid as three essential biological compounds at a carbon paste

electrode modified with copper oxide decorated reduced graphene oxide

nanocomposite and ionic liquid, J. Colloid Interface Sci. 560 (2020) 208-212. https://doi.org/10.1016/j.jcis.2019.10.007.

[32] M. Bijad, H. Karimi-Maleh, M. Farsi, S.A. Shahidi, An electrochemical-amplifiedplatform based on the nanostructure voltammetric sensor for the determination of carmoisine in the presence of tartrazine in dried fruit and soft drink samples, J. Food Meas. Charact. 12 (2018) 634-640. https://doi.org/10.1007/s11694-017-9676-1.

[33] F. Tahernejad-Javazmi, M. Shabani-Nooshabadi, H. Karimi-Maleh, Analysis of glutathione in the presence of acetaminophen and tyrosine via an amplified electrode with $\mathrm{MgO} / \mathrm{SWCNTs}$ as a sensor in the hemolyzed erythrocyte, Talanta. 176 (2018) 208-213. https://doi.org/10.1016/j.talanta.2017.08.027.

[34] O.E. Fayemi, A.S. Adekunle, Metal Oxide Nanoparticles/Multi-walled Carbon Nanotube Nanocomposite Modified Electrode for the Detection of Dopamine: Comparative Electrochemical Study, J. Biosens. Bioelectron. 06 (2015) 190. https://doi.org/10.4172/2155-6210.1000190. 
[35] J. Tashkhourian, S.F.F. Nami-Ana, A sensitive electrochemical sensor for 605 determination of gallic acid based on $\mathrm{SiO} 2$ nanoparticle modified carbon paste electrode, Mater. Sci. Eng. C. 52 (2015) 103-110. https://doi.org/10.1016/j.msec.2015.03.017.

[36] C.O. Chikere, N.H. Faisal, P. Kong-Thoo-Lin, C. Fernandez, Interaction between Amorphous Zirconia Nanoparticles and Graphite: Electrochemical Applications for Gallic Acid Sensing Using Carbon Paste Electrodes in Wine, Nanomaterials. 10 (2020) 537. https://doi.org/10.3390/nano10030537.

[37] E. Mehmeti, D.M. Stanković, S. Chaiyo, L. Švorc, K. Kalcher, Manganese dioxidemodified carbon paste electrode for voltammetric determination of riboflavin, Microchim. Acta. 183 (2016) 1619-1624. https://doi.org/10.1007/s00604-016-1789-4.

[38] Y. Zhao, S. Chen, B. Sun, D. Su, X. Huang, H. Liu, Y. Yan, K. Sun, G. Wang, Graphene-Co3O4 nanocomposite as electrocatalyst with high performance for oxygen evolution reaction, Sci. Rep. (2015). https://doi.org/10.1038/srep07629.

[39] Z.-Y. Li, P.T.M. Bui, D.-H. Kwak, M.S. Akhtar, O.-B. Yang, Enhanced electrochemical activity of low temperature solution process synthesized $\mathrm{Co} 3 \mathrm{O} 4$ nanoparticles for pseudo-supercapacitors applications, Ceram. Int. 42 (2016) 18791885. https://doi.org/10.1016/J.CERAMINT.2015.09.155.

[40] Y.I. Choi, H.J. Yoon, S.K. Kim, Y. Sohn, Crystal-facet dependent CO oxidation, preferential oxidation of $\mathrm{CO}$ in $\mathrm{H} 2$-rich, water-gas shift reactions, and supercapacitor application over Co3O4 nanostructures, Appl. Catal. A Gen. 519 (2016) 56-67. https://doi.org/10.1016/J.APCATA.2016.03.027.

[41] K.F. Wadekar, Nemade K.R., Waghuley S.A., Chemical synthesis of cobalt oxide (Co3O4) nanoparticles using Co-precipitation method, Res. J. Chem. Int. Sci. 
Community Assoc. Res. J. Chem. Sci. Res. J. Chem. Sci. 7 (2017) 53-55.

629 https://doi.org/10.1051/jp4:2001380.

630

631

632

633

634

635

636

637

638

639

640

641 643

[42] J. Yang, H. Liu, W.N. Martens, R.L. Frost, Synthesis and characterization of Cobalt hydroxide, cobalt oxyhydroxide, and cobalt oxide nanodiscs, J. Phys. Chem. C. 114 (2010) 111-119. https://doi.org/10.1021/jp908548f.

[43] N. Rani, G. Rani, M. Kumar, Green synthesis, characterization and optical properties of cobalt oxide nanoparticles by co-precipitation method, Int. J. Adv. Res. Dev. 3 (2018) 1195-1198.

[44] L. Estepa, M. Daudon, Contribution of Fourier transform infrared spectroscopy to the identification of urinary stones and kidney crystal deposits, Biospectroscopy. 3 (1997) $347-369$.

[45] F. Chekin, S.M. Vahdat, M.J. Asadi, Green synthesis and characterization of cobalt oxide nanoparticles and its electrocatalytic behavior, Russ. J. Appl. Chem. 89 (2016) 816-822. https://doi.org/10.1134/S1070427216050219.

$642[46]$ J. Tashkhourian, S.F. Nami-Ana, A sensitive electrochemical sensor for determination of gallic acid based on $\mathrm{SiO} 2$ nanoparticle modified carbon paste electrode, Mater. Sci. Eng. C. 52 (2015) 103-110. https://doi.org/10.1016/j.msec.2015.03.017.

[47] J.H. Luo, B.L. Li, N.B. Li, H.Q. Luo, Sensitive detection of gallic acid based on polyethyleneimine- functionalized graphene modified glassy carbon electrode, Sensors Actuators, B Chem. 186 (2013) 84-89. https://doi.org/10.1016/j.snb.2013.05.074.

[48] J. Tashkhourian, S.F.N. Ana, S. Hashemnia, M.R. Hormozi-Nezhad, Construction of a modified carbon paste electrode based on $\mathrm{TiO} 2$ nanoparticles for the determination of gallic acid, J. Solid State Electrochem. 17 (2013) 157-165. 
https://doi.org/10.1007/s10008-012-1860-y.

[49] I. Novak, M. Šeruga, Š. Komorsky-Lovrić, Electrochemical characterization of epigallocatechin gallate using square-wave voltammetry, Electroanalysis. 21 (2009) 1019-1025. https://doi.org/10.1002/elan.200804509.

[50] L.P. Souza, F. Calegari, A.J.G. Zarbin, L.H. Marcolino-Júnior, M.F. Bergamini, Voltammetric Determination of the Antioxidant Capacity in Wine Samples Using a Carbon Nanotube Modified Electrode, J. Agric. Food Chem. 59 (2011) 7620-7625. https://doi.org/10.1021/jf2005589.

[51] A.E. Fazary, M. Taha, Y.H. Ju, Iron complexation studies of gallic acid, J. Chem. Eng. Data. 54 (2009) 35-42. https://doi.org/10.1021/je800441u.

[52] P. a Kilmartin, H. Zou, A.L. Waterhouse, A Cyclic Voltammetry Method Suitable for Characterizing Antioxidant Properties of Wine and Wine Phenolics A Cyclic Voltammetry Method Suitable for Characterizing Antioxidant Properties of Wine and Wine Phenolics, J. Agric. Food Chem. 49 (2001) 1957-1965. https://doi.org/10.1021/jf001044u.

[53] O. Makhotkina, P.A. Kilmartin, Uncovering the influence of antioxidants on polyphenol oxidation in wines using an electrochemical method: Cyclic voltammetry, J. Electroanal. Chem. 633 (2009) 165-174. https://doi.org/10.1016/j.jelechem.2009.05.007.

[54] M. López-Vélez, F. Martínez-Martínez, C. Del Valle-Ribes, The Study of Phenolic Compounds as Natural Antioxidants in Wine, Crit. Rev. Food Sci. Nutr. 43 (2003) 233-244. https://doi.org/10.1080/727072831. 

salento, Foods. 8 (2019) 45. https://doi.org/10.3390/foods8020045. 


\section{Electroanalytical determination of gallic acid in Red and White wine samples using Cobalt Oxide Nanoparticles-modified carbon- paste electrodes}

\section{Chrys. O. CHIKERE ${ }^{\text {a }}$ Emma HOBBEN ${ }^{\text {, }}$, Nadimul Haque FAISAL ${ }^{\text {, }}$ Paul KONG- THOO-LINa, Carlos FERNANDEZ ${ }^{a *}$}

a. School of Pharmacy and Life Sciences, the Robert Gordon University, Aberdeen, AB10 7GJ, United Kingdom

b. School of Engineering, the Robert Gordon University, Aberdeen AB10 7GJ, United Kingdom

*Corresponding Author.Tel.+44 (0) 1224262559 E-mail: c.fernandez@,rgu.ac.uk

\section{LIST OF FIGURES}

Fig 1. (a) The SEM Image of Cobalt oxide nanoparticles showing the morphology of the nanoparticles with (Inset) $\mathrm{Co}_{3} \mathrm{O}_{4}$ in $100 \mathrm{~nm}$ (b) SEM Image of CoO-nano-CPE, with the paraffin holding the Cobalt oxide nanoparticles and graphite together (c) EDXA analysis of Cobalt oxide nanoparticles (d) Size distribution of cobalt oxide nanoparticles using a Zetasizer..

Fig 2. (a) Cyclic voltammetry of GA $\left(10 \mathrm{mmol} \mathrm{L}^{-1}\right)$ at the CoO-NPs-CPE and bare CPE in $1 \times 10^{2}$ mmol L-1 phosphate buffer of $\mathrm{pH} 2.0$ at a scan rate of $100 \mathrm{mVs}^{-1}$. (b) The cyclic voltammograms of 5 mmol L-1 $\left[\mathrm{Fe}(\mathrm{CN})_{6}\right]^{3-/ 4-}$ redox solution, using bare CPE and CoO-NPs-CPE, (c) Nyquist plot showing the EIS measurements of $\left[\mathrm{Fe}(\mathrm{CN})_{6}\right]^{3-/ 4-}\left(5 \mathrm{mmol} \mathrm{L}^{-1}\right)$ using the bare CPE and CoO-NPs-CPE (inset) The equivalent circuit used for the calculation.

Fig 3. Cyclic voltammograms of $10 \mathrm{mmol} \mathrm{L}^{-1} \mathrm{GA}$ at $\mathrm{Co}_{3} \mathrm{O}_{4}$ nanoparticles-modified $\mathrm{CPE}$, bulk $\mathrm{Co}_{3} \mathrm{O}_{4}$ nanoparticles-modified CPE and bare CPE in $1 \times 10^{2} \mathrm{mmol} \mathrm{L}^{-1}$ phosphate buffer of $\mathrm{pH} 2.0$ at a scan rate of $100 \mathrm{mVs}^{-1}$

Fig 4. (a) Differential voltammograms of various concentrations of GA at CoO-nano-CPE in a $1 \times 10^{-}$ 2 mmol L-1 phosphate buffer at $\mathrm{pH} 2.0$ at scan rate of $100 \mathrm{mVs}^{-1}$, with voltammograms (a-j) that corresponds to the following concentrations a) Blank PBS, b) $1 \times 10^{-4} \mathrm{mmol} \mathrm{L}^{-1}$, c) $2.5 \times 10^{-4} \mathrm{mmol} \mathrm{L}^{-}$ 1, d) $5 \times 10^{-4} \mathrm{mmol} \mathrm{L}^{-1}$, e) $7.5 \times 10^{-4} \mathrm{mmol} \mathrm{L}^{-1}$, f) $1 \times 10^{-3} \mathrm{mmol} \mathrm{L}-1$, g) $2.5 \times 10^{-3} \mathrm{mmol} \mathrm{L}^{-1}$, h) $5 \times 10^{-3}$ mmol L-1, i) $7.5 \times 10^{-3} \mathrm{mmol} \mathrm{L}^{-1}, \mathrm{j}$ ) $1 \times 10^{-2} \mathrm{mmol} \mathrm{L}^{-1}$ (inset) Plot of concentration of GA against peak currents. (b) The plot of the Peak Current $\left(\mathrm{I}_{\mathrm{p}}\right)$ against the concentration of GA, showing the effect of 
concentration on the electrochemical behaviour of increasing GA concentration, using CoO-nano-CPE at a scan rate of $100 \mathrm{mVs}^{-1}$

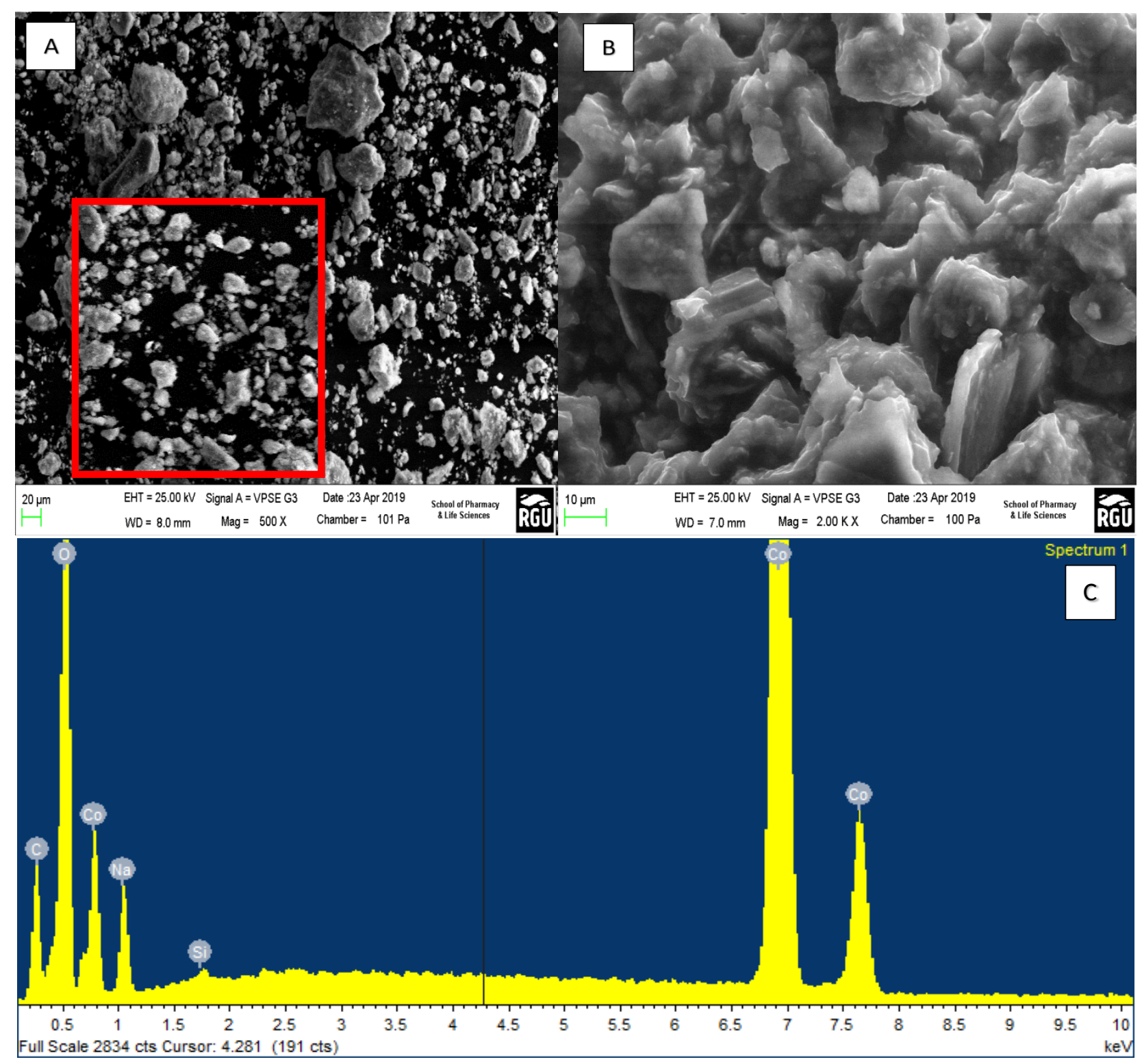


Results

$\begin{array}{rlllll} & & & \text { Size (d.nm): } & \text { \% Intensity: } & \text { St Dev (d.n... } \\ \text { Z-Average (d.nm): } & 279.4 & \text { Peak 1: } & 288.2 & 83.3 & 144.5 \\ \text { Pdl: } & 0.250 & \text { Peak 2: } & 1835 & 16.7 & 871.6 \\ \text { Intercept: } & 0.909 & \text { Peak 3: } & 0.000 & 0.0 & 0.000 \\ \text { Result quality : } & \text { Good } & & & & \end{array}$

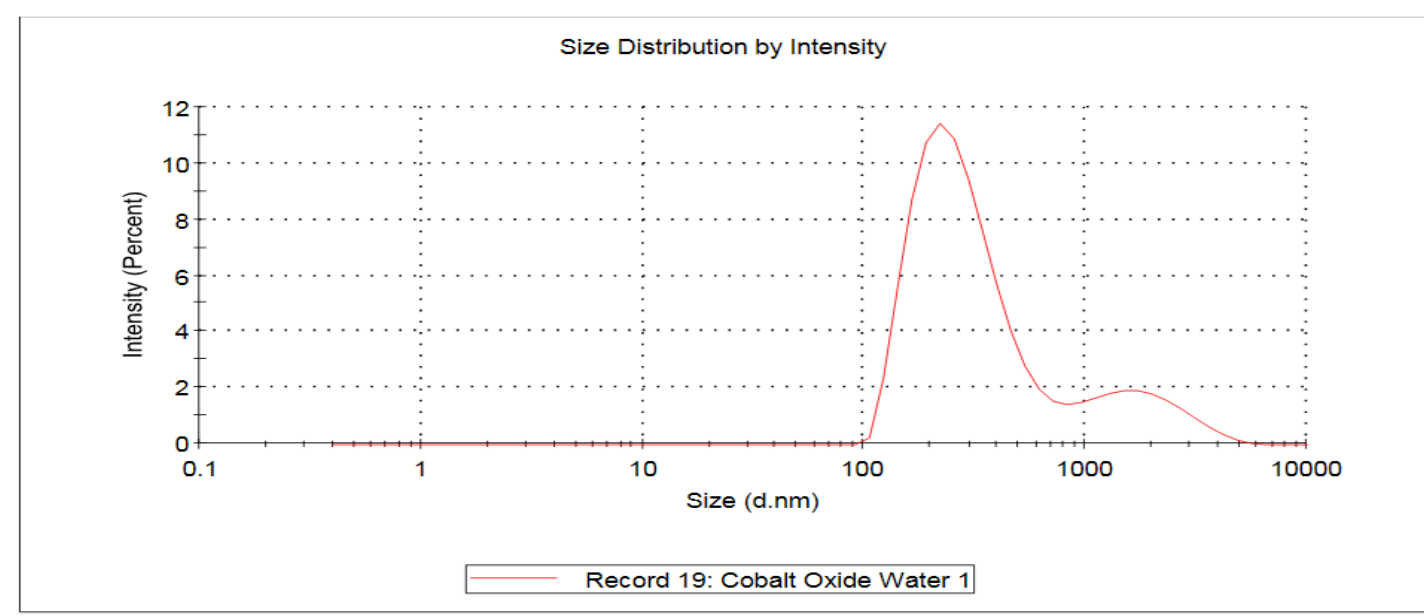

Fig 1. (a) The SEM Image of Cobalt oxide nanoparticles showing the morphology of the nanoparticles with (Inset) $\mathrm{Co}_{3} \mathrm{O}_{4}$ in $100 \mathrm{~nm}$ (b) SEM Image of CoO-nano-CPE, with the paraffin holding the Cobalt oxide nanoparticles and graphite together (c) EDXA analysis of Cobalt oxide nanoparticles (d) Size distribution of cobalt oxide nanoparticles using a Zetasizer. 

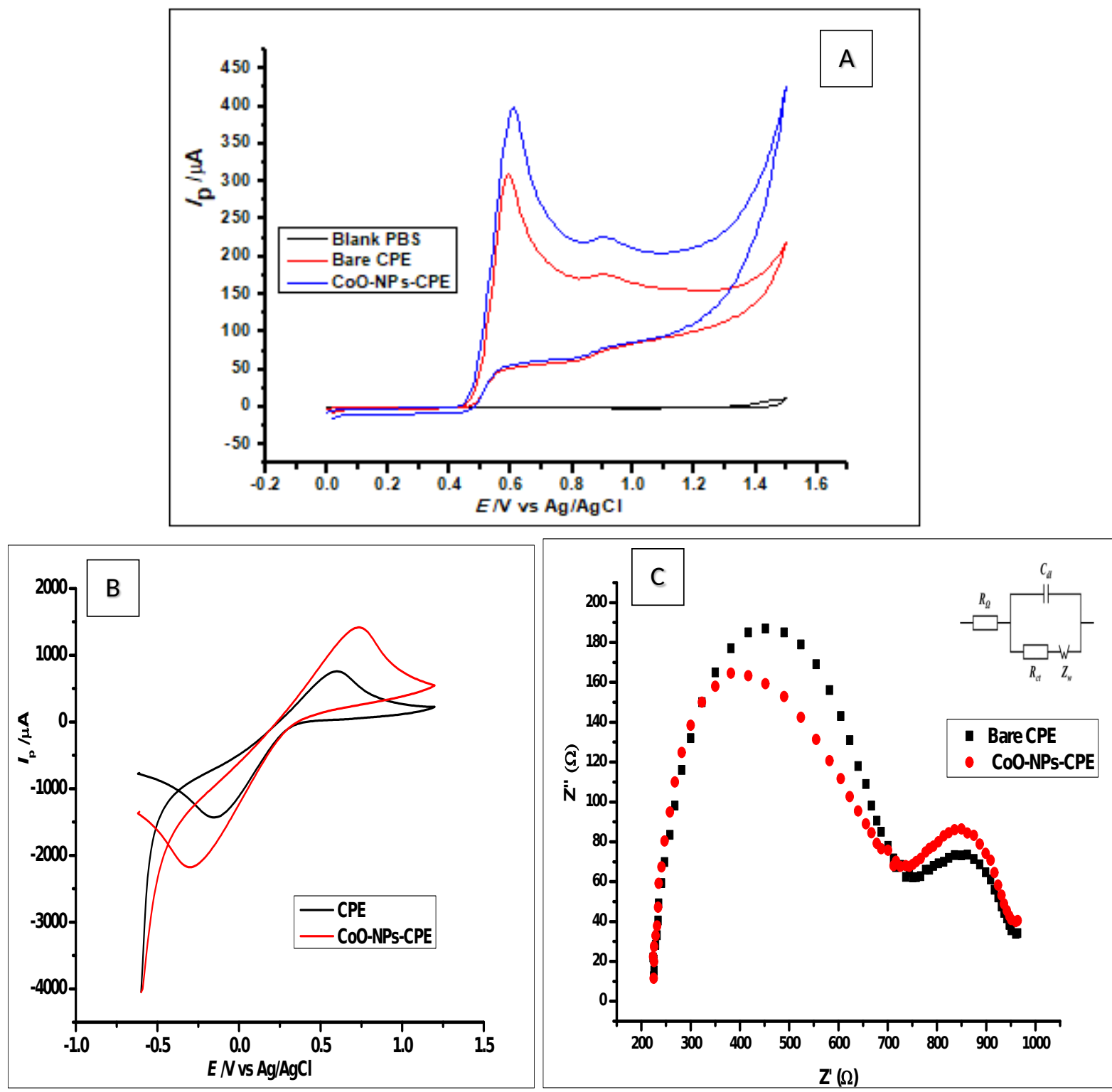

Fig 2. (a) Cyclic voltammetry of GA $\left(10 \mathrm{mmol} \mathrm{L}^{-1}\right)$ at the CoO-NPs-CPE and bare CPE in $1 \times 10^{2}$ mmol L-1 phosphate buffer of $\mathrm{pH} 2.0$ at a scan rate of $100 \mathrm{mVs}^{-1}$. (b) The cyclic voltammograms of 5 mmol L-1 $\left[\mathrm{Fe}(\mathrm{CN})_{6}\right]^{3-4-}$ redox solution, using bare $\mathrm{CPE}$ and CoO-NPs-CPE, (c) Nyquist plot showing the EIS measurements of $\left[\mathrm{Fe}(\mathrm{CN})_{6}\right]^{3-/ 4-}\left(5 \mathrm{mmol} \mathrm{L}^{-1}\right)$ using the bare CPE and CoO-NPs-CPE (inset) The equivalent circuit used for the calculation. 


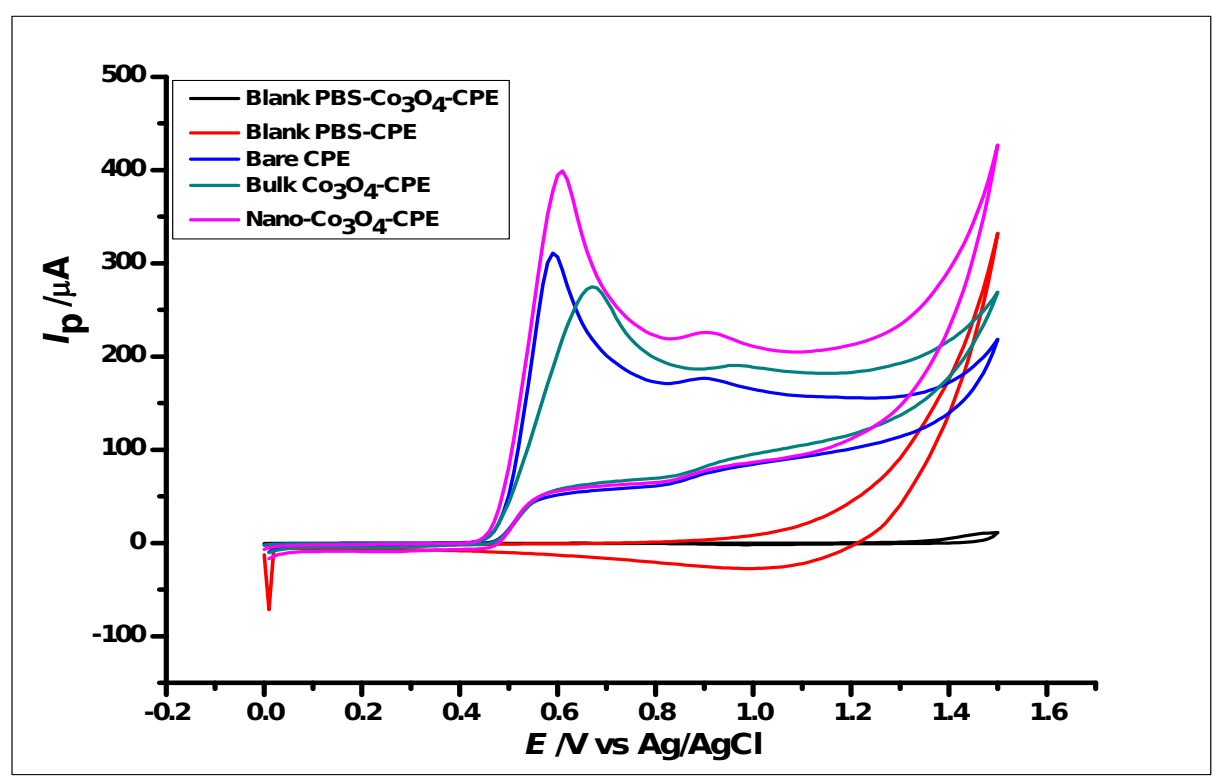

Fig 3. Cyclic voltammograms of $10 \mathrm{mmol} \mathrm{L}^{-1} \mathrm{GA}$ at $\mathrm{Co}_{3} \mathrm{O}_{4}$ nanoparticles-modified CPE, bulk $\mathrm{Co}_{3} \mathrm{O}_{4}$ nanoparticles-modified CPE and bare CPE in $1 \times 10^{2} \mathrm{mmol} \mathrm{L}^{-1}$ phosphate buffer of $\mathrm{pH} 2.0$ at a scan rate of $100 \mathrm{mVs}^{-1}$ 

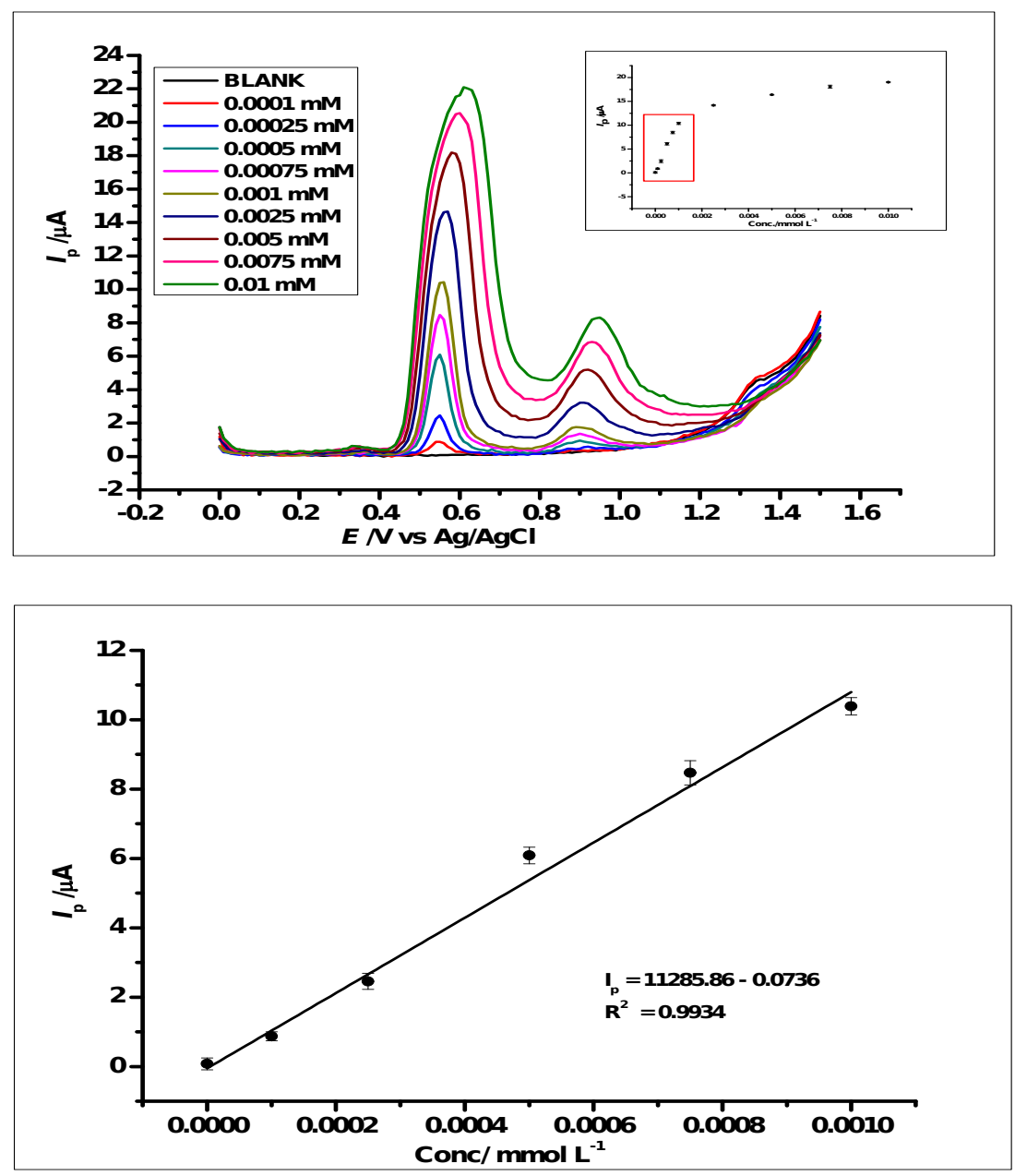

Fig 4. (a) Differential voltammograms of various concentrations of GA at CoO-nano-CPE in a 0.1 mol L-1 phosphate buffer at $\mathrm{pH} 2.0$ at scan rate of $100 \mathrm{mVs}^{-1}$, with voltammograms (a-j) that corresponds to the following concentrations a) Blank PBS, b) $1 \times 10^{-4} \mathrm{mmol} \mathrm{L}^{-1}$, c) $2.5 \times 10^{-4} \mathrm{mmol} \mathrm{L}^{-}$ , d) $5 \times 10^{-4} \mathrm{mmol} \mathrm{L}^{-1}$, e) $7.5 \times 10^{-4} \mathrm{mmol} \mathrm{L}^{-1}$, f) $1 \times 10^{-3} \mathrm{mmol} \mathrm{L}^{-1}$, g) $2.5 \times 10^{-3} \mathrm{mmol} \mathrm{L}^{-1}$, h) $5 \times 10^{-3}$ mmol L-1, i) $7.5 \times 10^{-3} \mathrm{mmol} \mathrm{L}^{-1}$, j) $1 \times 10^{-2} \mathrm{mmol} \mathrm{L}^{-1}$ (inset) Plot of concentration of GA against peak currents. (b) The plot of the Peak Current $\left(\mathrm{I}_{\mathrm{p}}\right)$ against the concentration of GA, showing the effect of concentration on the electrochemical behaviour of increasing GA concentration, using CoOnano-CPE at a scan rate of $100 \mathrm{mVs}^{-1}$ 


\section{Electroanalytical determination of gallic acid in Red and White wine samples using Cobalt Oxide Nanoparticles-modified carbon- paste electrodes}

Chrys. O. CHIKEREa , Emma HOBBENa, Nadimul Haque FAISAL ${ }^{\text {b }}$, Paul KONGTHOO-LIN ${ }^{a}$, Carlos FERNANDEZ ${ }^{\text {a }}$

a. School of Pharmacy and Life Sciences, the Robert Gordon University, Aberdeen, AB10 7GJ, United Kingdom

b. School of Engineering, the Robert Gordon University, Aberdeen AB10 7GJ, United Kingdom

*Corresponding Author.Tel.+44 (0) 1224262559 E-mail: c.fernandez@.rgu.ac.uk

\section{List of tables}

Table 1. The absorbance values of GA $\left(1 \times 10^{-3} \mathrm{~mol} \mathrm{~L}^{-1}\right)$ at different $\mathrm{pH}$ at the wavelength of $280 \mathrm{~nm}$

\begin{tabular}{|c|c|c|}
\hline & pH Values & Absorbance (Wavelength 280 nm) \\
\hline 1 & 2.0 & $2.205 \pm 0.02$ \\
\hline 2 & 4.0 & $3.09 \pm 0.02$ \\
\hline 3 & 6.0 & $3.52 \pm 0.06$ \\
\hline 4 & 8.0 & $33.92 \pm 0.6$ \\
\hline 5 & 10 & $37.49 \pm 0.15$ \\
\hline
\end{tabular}

Table 2. Metal Oxide Nanoparticles (MO-NPs) and Metal Nanoparticles composites in different electrochemical sensor systems for the determination of Gallic acid.

\begin{tabular}{|c|c|c|c|c|c|c|}
\hline & Electrodes & Method & $\begin{array}{l}\text { Medium } \\
\text { Analysed }\end{array}$ & $\begin{array}{c}\text { Linear } \\
\text { Range (mol } \\
\left.\mathrm{L}^{-1}\right)\end{array}$ & $\begin{array}{c}\text { Limit of } \\
\text { Detection } \\
\left(\mathrm{mol} \mathrm{L}^{-1}\right)\end{array}$ & Reference \\
\hline 1 & ZnO-NPs-CPE & CV, DPV & Red Wine & $\begin{array}{c}1 \times 10^{-6}- \\
5 \times 10^{-5}\end{array}$ & $1.86 \times 10^{-7}$ & [25] \\
\hline 2 & $\begin{array}{c}\mathrm{SiO}_{2}-\mathrm{NPs}-\mathrm{GrO} \\
\text { nanocolloids-GCE }\end{array}$ & $\mathrm{CV}, \mathrm{DPV}$ & $\begin{array}{c}\text { Red and } \\
\text { White wine }\end{array}$ & $\begin{array}{c}6.25 \times 10^{-6} \text { to } \\
1 \times 10^{-3}\end{array}$ & $2.09 \times 10^{-6}$ & [22] \\
\hline
\end{tabular}




\begin{tabular}{|c|c|c|c|c|c|c|}
\hline 3 & $\begin{array}{c}\text { Amorphous Zirconia- } \\
\text { CPE }\end{array}$ & CV, DPV & $\begin{array}{c}\text { Red and } \\
\text { White Wine }\end{array}$ & $\begin{array}{c}1 \times 10^{-6}- \\
1 \times 10^{-3}\end{array}$ & $1.24 \times 10^{-7}$ & [36] \\
\hline 4 & $\mathrm{ZrO}_{2} / \mathrm{Co}_{3} \mathrm{O}_{4} / \mathrm{rGO}-\mathrm{FTO}$ & CV, DPV & $\begin{array}{c}\text { Fruit juice, } \\
\text { Tea }\end{array}$ & $\begin{array}{c}6.24 \times 10^{-9}- \\
4.8 \times 10^{-7}\end{array}$ & $1.56 \times 10^{-9}$ & [26] \\
\hline 5 & $\begin{array}{l}\text { Bismuth-NPs-MWCNT- } \\
\text { CPE }\end{array}$ & $\begin{array}{c}\mathrm{CV}, \\
\text { Amperometry }\end{array}$ & $\begin{array}{l}\text { Clove and } \\
\text { Green Tea }\end{array}$ & $\begin{array}{c}1 \times 10^{-6}-1 \\
\times 10^{-4}\end{array}$ & $1.6 \times 10^{-7}$ & {$[14]$} \\
\hline 6 & $\mathrm{TiO}_{2}$-NPS-CPE & $\mathrm{CV}, \mathrm{DPV}$ & $\begin{array}{l}\text { Green and } \\
\text { Black Tea }\end{array}$ & $\begin{array}{l}2.5 \times 10^{-6}- \\
1.5 \times 10^{-4}\end{array}$ & $9.4 \times 10^{-7}$ & [48] \\
\hline 7 & CoO-NPS-CPE & $\mathrm{CV}, \mathrm{DPV}$ & $\begin{array}{c}\text { Red and } \\
\text { White Wine }\end{array}$ & $\begin{array}{c}1 \times 10^{-4} \text { to } 1 \times \\
10^{-2}\end{array}$ & $1.52 \times 10^{-6}$ & This Work \\
\hline
\end{tabular}

Table 3. Results of the analysis of GA in spiked Red Wine and White Wine

\begin{tabular}{|c|c|c|c|c|}
\hline \multirow[b]{2}{*}{ Sample } & \multicolumn{4}{|c|}{ Australian Wine } \\
\hline & $\begin{array}{c}\text { Added } \\
\left(\mathrm{mmol} \mathrm{L}^{-1}\right)\end{array}$ & $\begin{array}{c}\text { Found } \\
\left(\mathrm{mmol} \mathrm{L}^{-1}\right)\end{array}$ & Relative Error & Recovery (\%) \\
\hline \multirow[t]{4}{*}{ Red Wine } & 0.0 & 0.688 & - & - \\
\hline & 0.9 & 0.787 & \pm 13 & 87 \\
\hline & 1.6 & 1.599 & \pm 0.7 & 99.93 \\
\hline & 2.31 & 2.35 & \pm 1.73 & 101.73 \\
\hline \multirow{6}{*}{ White Wine } & 00 & 0076 & - & - \\
\hline & 0.9 & 0.995 & \pm 10.5 & 110.5 \\
\hline & 1.6 & 1.658 & \pm 3.63 & 103.63 \\
\hline & 2.31 & 2.23 & \pm 3.46 & 96.54 \\
\hline & \multicolumn{4}{|c|}{ United States of America Wine } \\
\hline & $\begin{array}{c}\text { Added } \\
\left(\mathrm{mmol} \mathrm{L}^{-1}\right)\end{array}$ & $\begin{array}{c}\text { Found } \\
\left(\mathrm{mmol} \mathrm{L}^{-1}\right)\end{array}$ & Relative Error & Recovery (\%) \\
\hline \multirow[t]{4}{*}{ Red Wine } & 0.0 & 0.844 & - & - \\
\hline & 0.9 & 0.931 & \pm 3.4 & 103.4 \\
\hline & 1.6 & 1.501 & \pm 6.19 & 93.81 \\
\hline & 2.31 & 2.33 & \pm 0.87 & 100.87 \\
\hline \multirow{4}{*}{ White Wine } & 0.0 & 0.0083 & - & - \\
\hline & 0.9 & 0.911 & \pm 1.2 & 101.2 \\
\hline & 1.6 & 1.582 & \pm 1.12 & 98.88 \\
\hline & 2.31 & 2.271 & \pm 1.69 & 98.31 \\
\hline
\end{tabular}




\section{Conflict of interest}

Dr. Chrys. O. Chikere declares that he has no conflict of interest. Ms. Emma Hobben declares that she has no conflict of interest. Dr. Nadimul H Faisal declares that he has no conflict of interest. Professor Paul Kong-Thoo-Lin declares that he has no conflict of interest. Dr. Carlos Fernandez declares that he has no conflict of interest. 


\section{Electroanalytical determination of gallic acid in Red and White wine samples using Cobalt Oxide Nanoparticles-modified carbon- paste electrodes}

Chrys. O. CHIKEREa, Emma HOBBENa, Nadimul Haque FAISAL ${ }^{\text {b }}$, Paul Kong THOO-LIN ${ }^{a}$, Carlos FERNANDEZ ${ }^{\text {a }}$

a. School of Pharmacy and Life Sciences, the Robert Gordon University, Aberdeen, AB10 7GJ, United Kingdom

b. School of Engineering, the Robert Gordon University, Aberdeen AB10 7GJ, United Kingdom

*Corresponding Author.Tel.+44 (0) 1224262559 E-mail: c.fernandez@.rgu.ac.uk

\section{Electronic Supplementary Material}

S1 The FTIR Characterisation

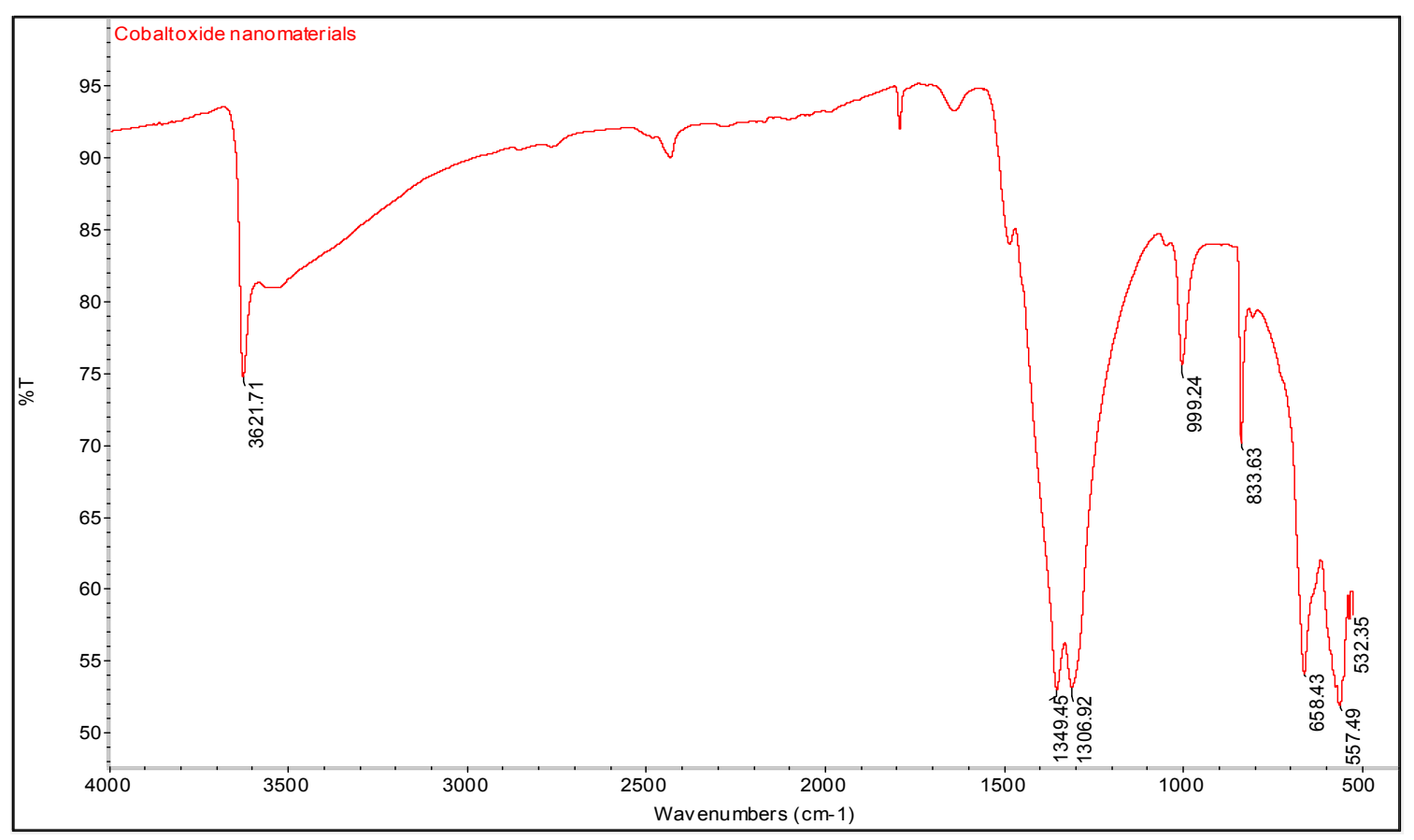

Fig. S1. FT-IR Image showing the spectra of $\mathrm{Co}_{3} \mathrm{O}_{4}$ nanoparticles 


\section{S2 The Thermogravimetric Analysis (TGA)}

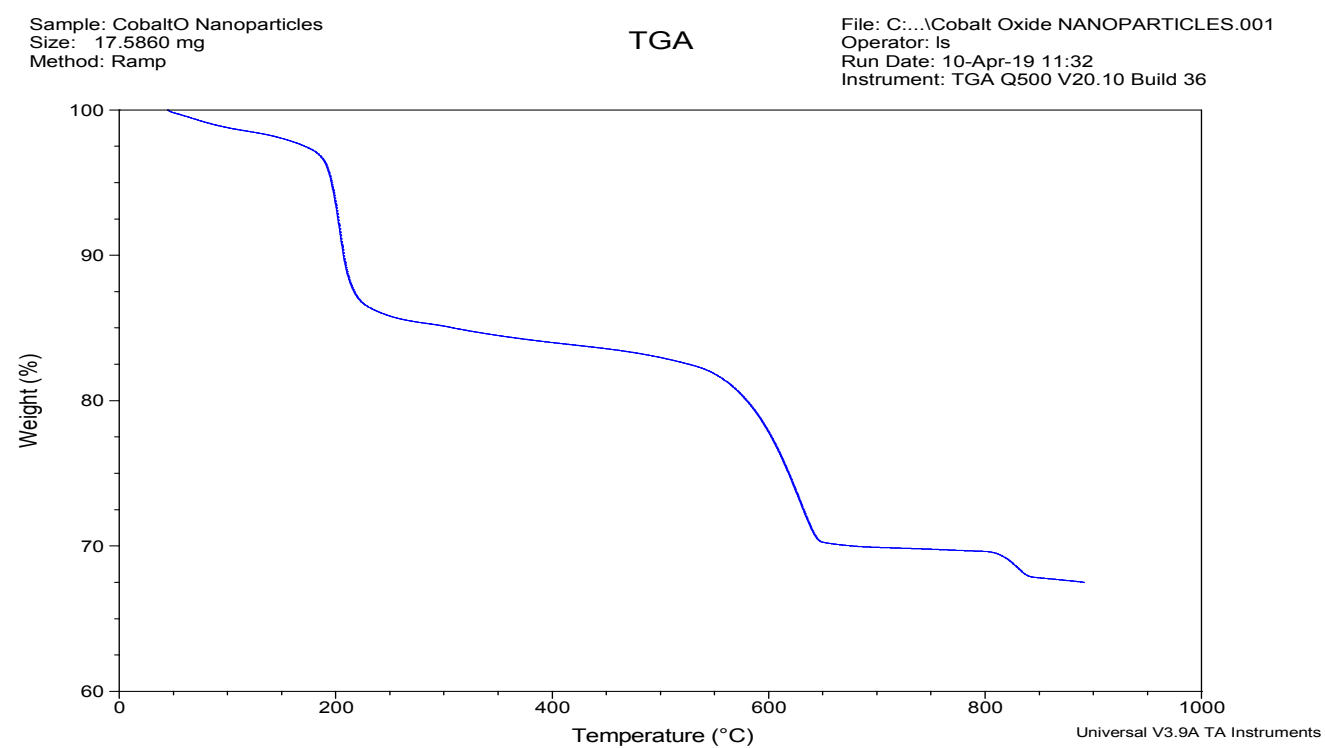

Fig S2. TGA result in the analysis of cobalt oxide nanoparticles

\section{S3 Effective Surface Area Measurement}
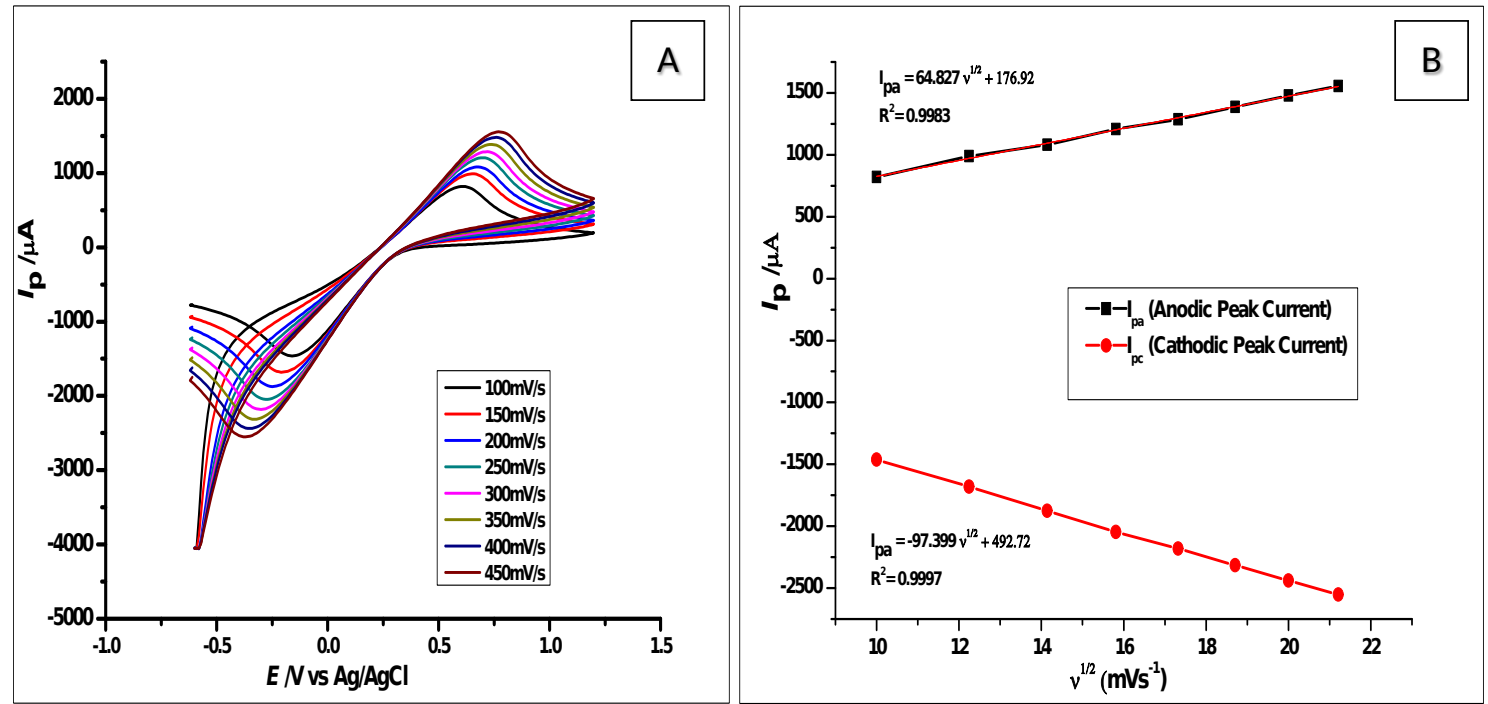

Fig. S3. (a) Cyclic voltammograms of $\left[\mathrm{Fe}(\mathrm{CN})_{6}\right]^{3-/ 4-}\left(1 \mathrm{mmol} \mathrm{L}^{-1}\right)$ measured with $\mathrm{CoO}-\mathrm{NPs}-\mathrm{CPE}$ at increasing scan rates of $100-450 \mathrm{mVs}^{-1}$ (b) Plots of $I_{\mathrm{p}}$ vs $v^{1 / 2}$ used for the calculation of the reactive surface area. 
S4 The Reaction Mechanism of Gallic Acid oxidation

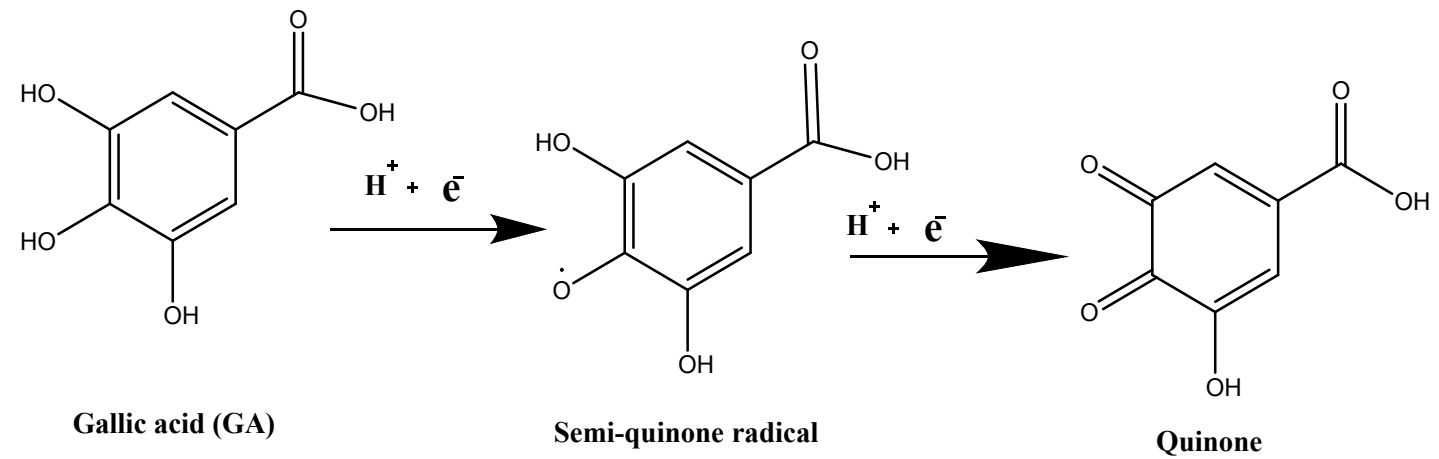

Fig. S4. The reaction mechanism of the oxidation of Gallic acid, showing the two peaks (semiquinone radical and the quinone)

\section{S5 Effect of pH on Gallic acid Oxidation}
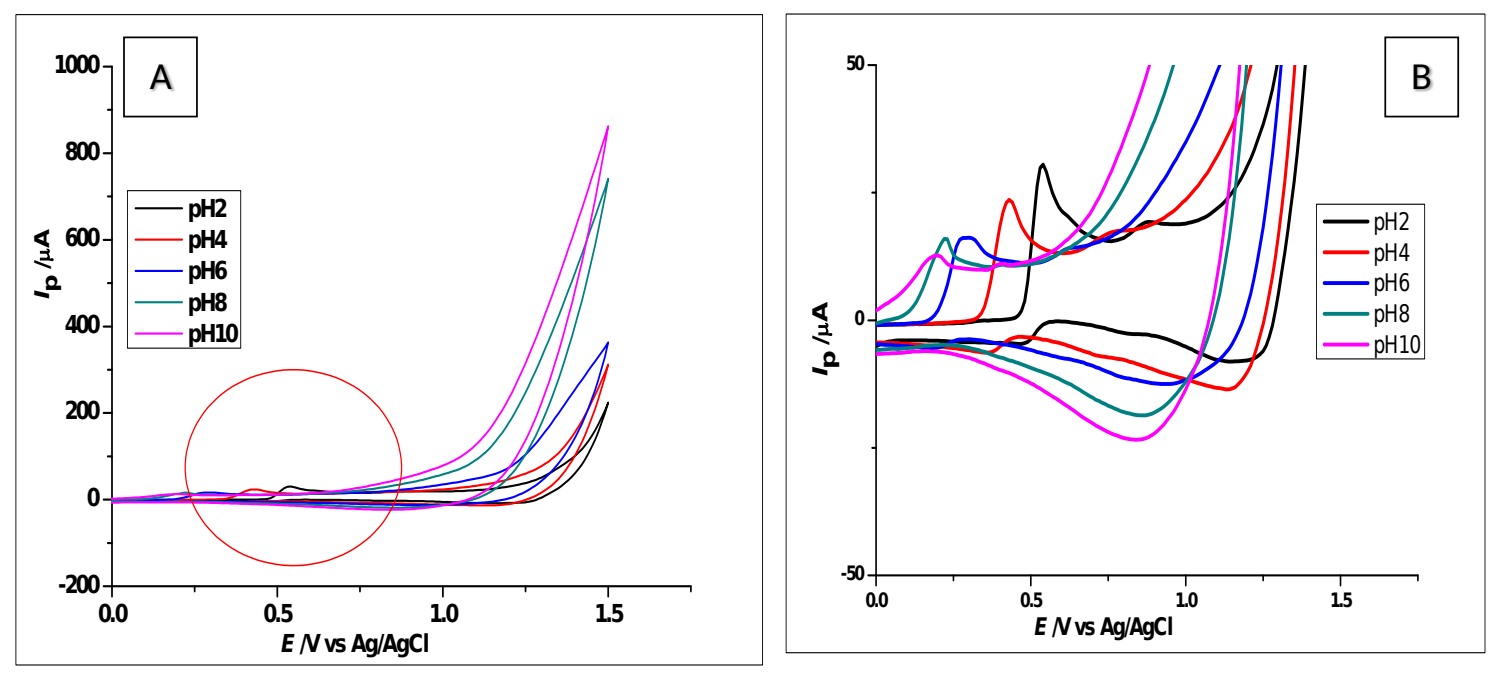

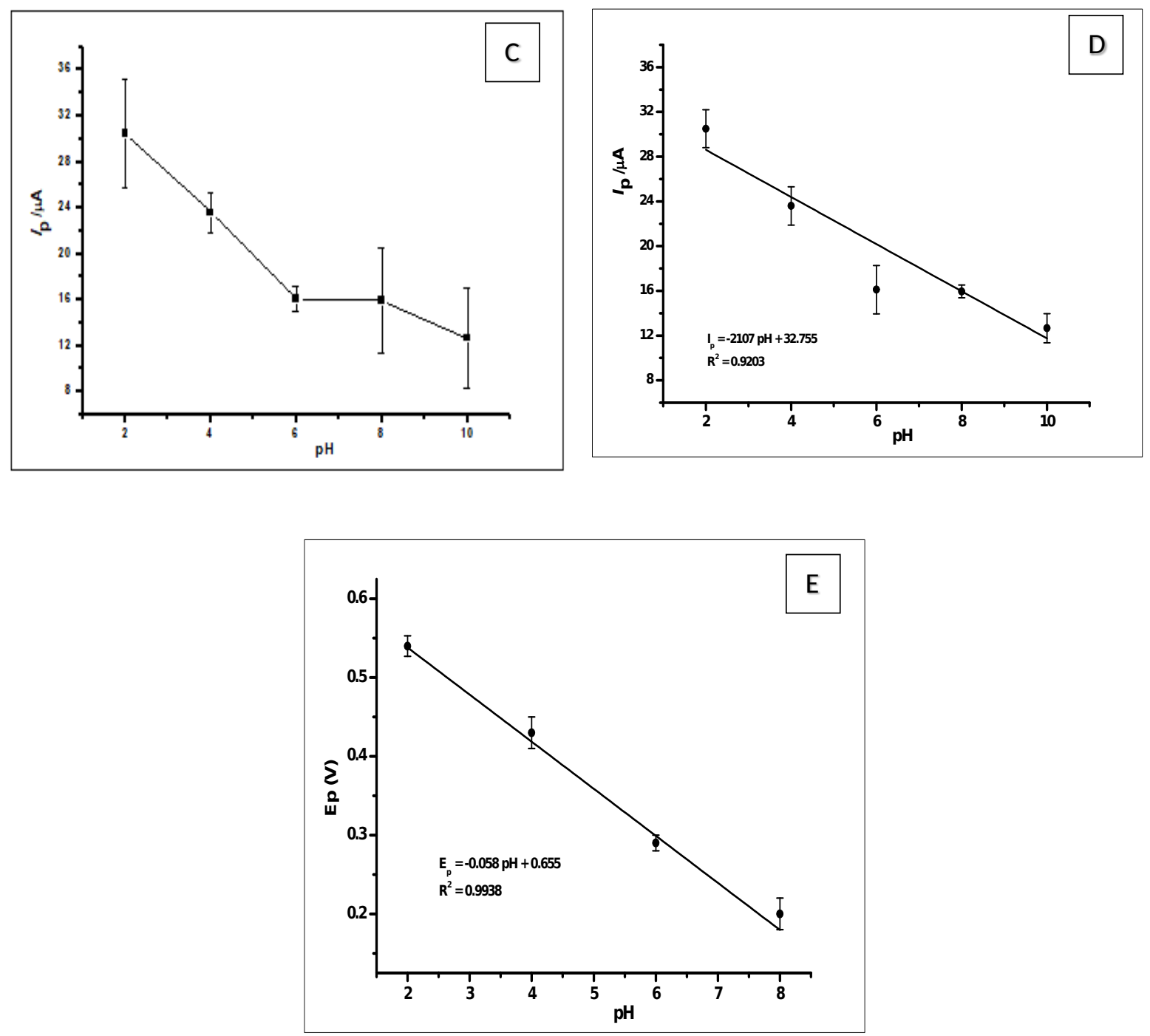

Fig. S5 (a) Cyclic voltammograms of $1 \times 10^{-3} \mathrm{~mol} \mathrm{~L}^{-1} \mathrm{GA}$ in the different $\mathrm{pH}$ range of 2.0 to 10.0 at a scan rate $100 \mathrm{mVs}^{-1}$ (b) Zoomed section of the voltammograms (c) A graph of $\mathrm{pH}$ against the peak currents (d) Non-linear plot of peak current $\left(I_{\mathrm{p}}\right) \mathrm{vs} \mathrm{pH}$ (e) Linear plot of peak potential $\left(E_{\mathrm{p}}\right) \mathrm{vs} \mathrm{pH}$ 


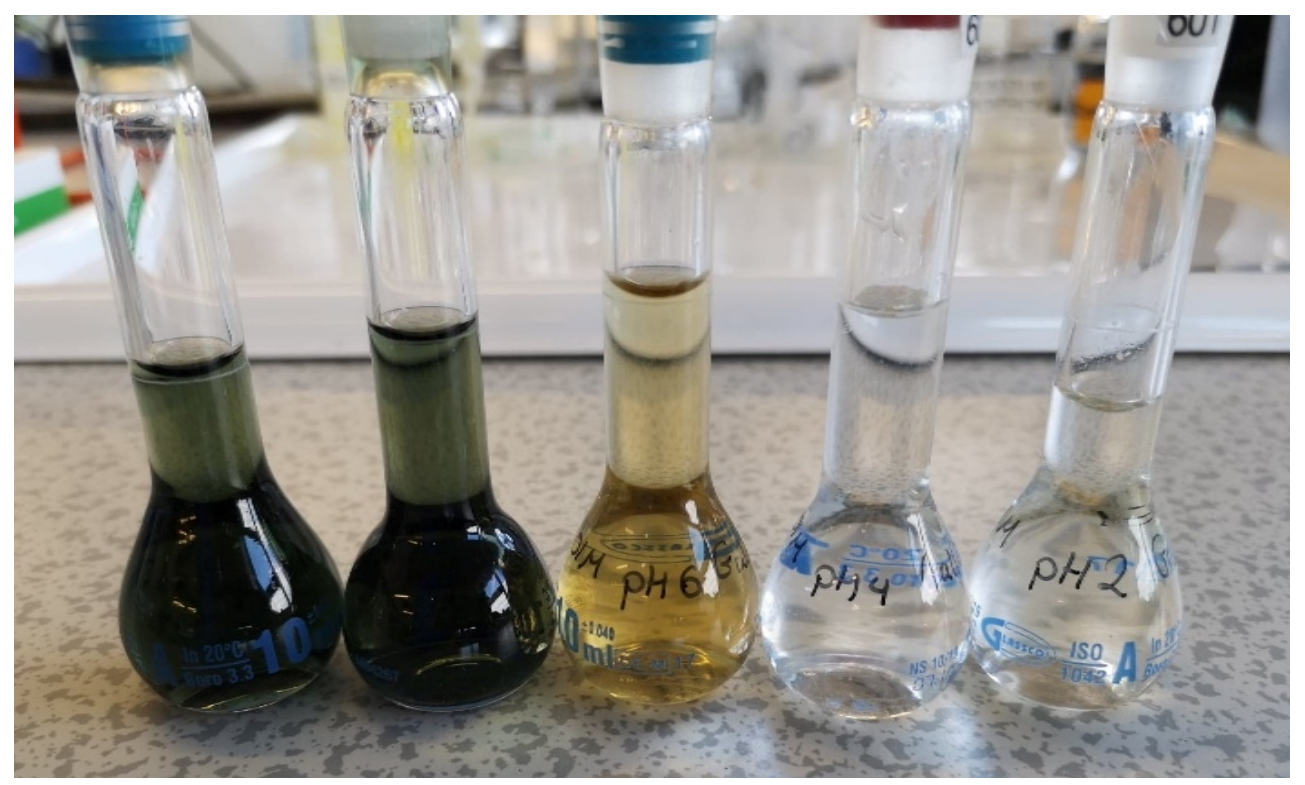

Fig. S6. Images of Gallic acid solutions at different $\mathrm{pH}$, showing a very dark solution at a $\mathrm{pH} 10$, that becomes brighter as the $\mathrm{pH}$ reduces to $\mathrm{pH} 8$ to $\mathrm{pH} 2$.

\section{S7. Effect of Scan rate on Gallic acid oxidation}
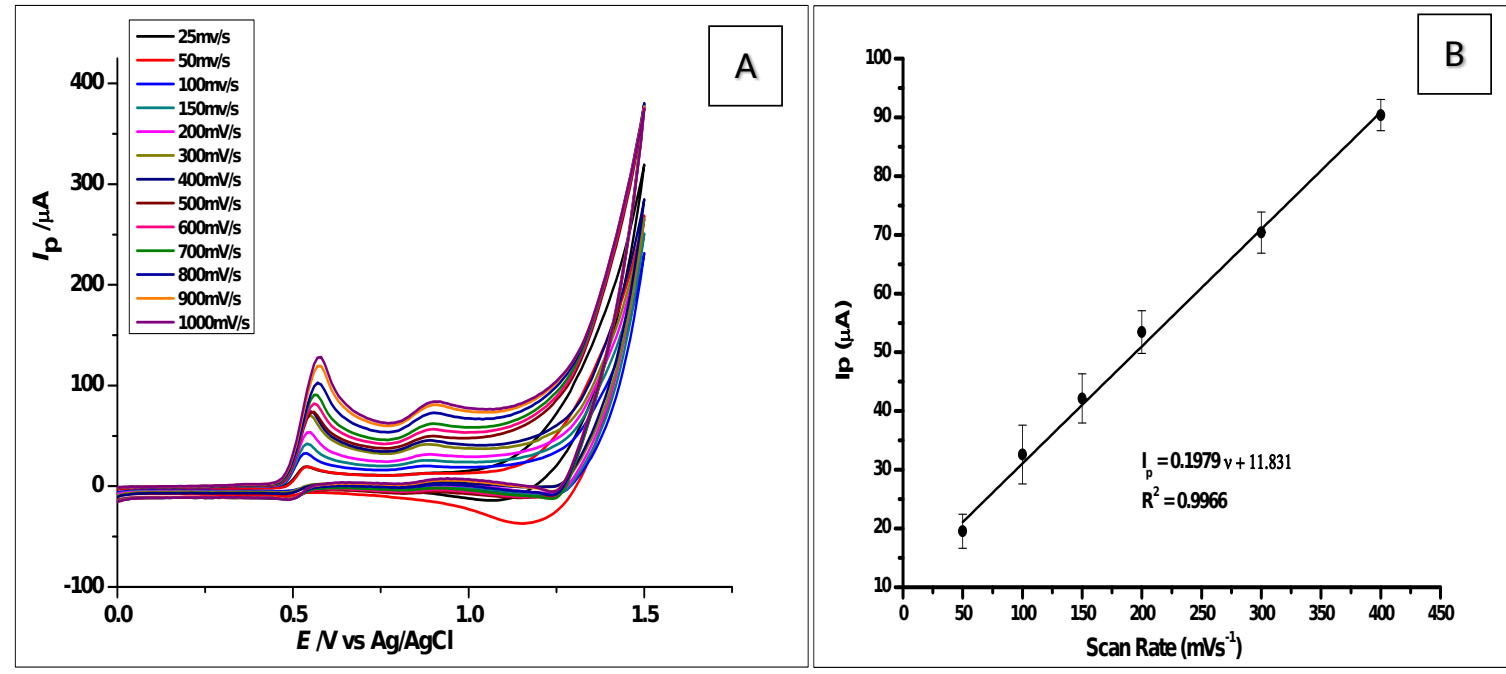

Fig. S7 (a) CV voltammograms of $1 \times 10^{-3} \mathrm{~mol} \mathrm{~L}^{-1} \mathrm{GA}$ in $1 \times 10^{-1} \mathrm{~mol} \mathrm{~L}^{-1}$ Phosphate buffer solution at $\mathrm{pH}$ 2.0, showing different scan rates ranging from $50-1000 \mathrm{mVs}^{-1}$ (b) Plot of the scan rates from 50$400 \mathrm{mVs}^{-1}$ against the peak current. 


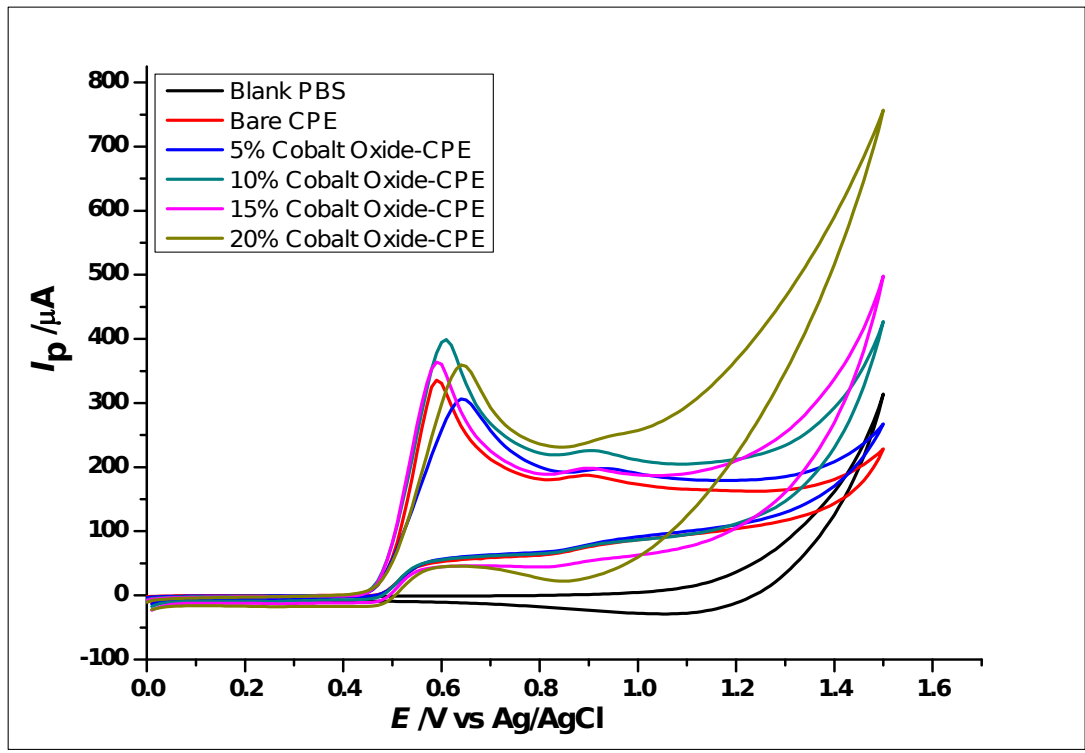

Fig.S8 Voltammograms showing changes in the constitution of the carbon paste electrode using 5\%, $10 \%, 15 \%$ and $20 \%$ Cobalt oxide nanoparticles constituted in the modified CPE. This was used to determine $1 \times 10^{-2} \mathrm{~mol} \mathrm{~L}^{-1} \mathrm{GA}$ in $1 \times 10^{-1} \mathrm{~mol} \mathrm{~L}^{-1}$ phosphate buffer at $\mathrm{pH} 2.0$ using $\mathrm{CV}$ at a scan rate of $100 \mathrm{mVs}^{-1}$

\section{S9 Reproducibility and repeatability of the method}
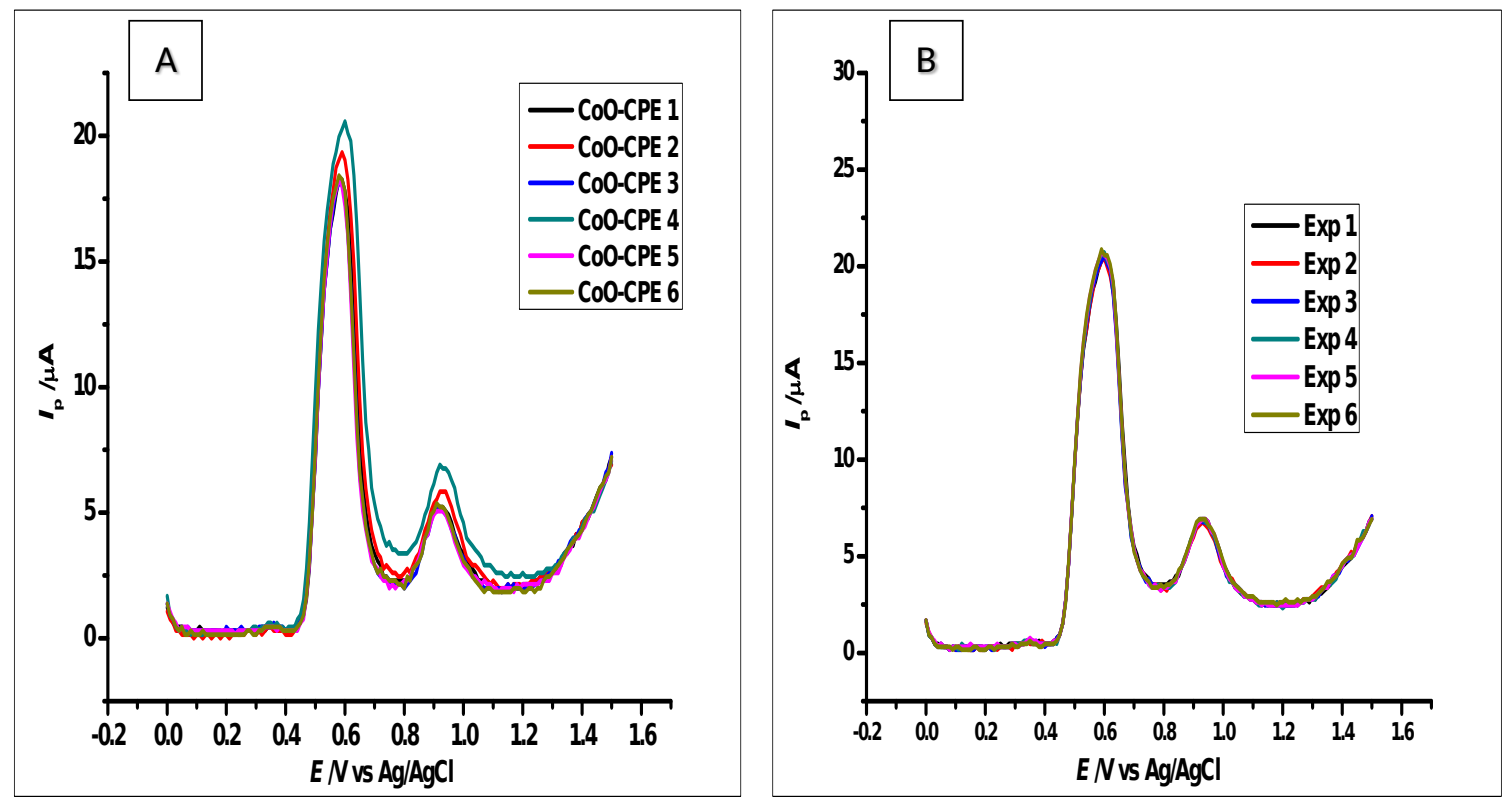
Fig. S9 DPV voltammograms of $5 \times 10^{-4} \mathrm{~mol} \mathrm{~L}^{-1}$ Gallic acid showing (a) Reproducibility of the CoO nanoparticles modified CPE (b) Repeatability of the CoO nanoparticles modified CPE

\section{S10 Stability of the method}

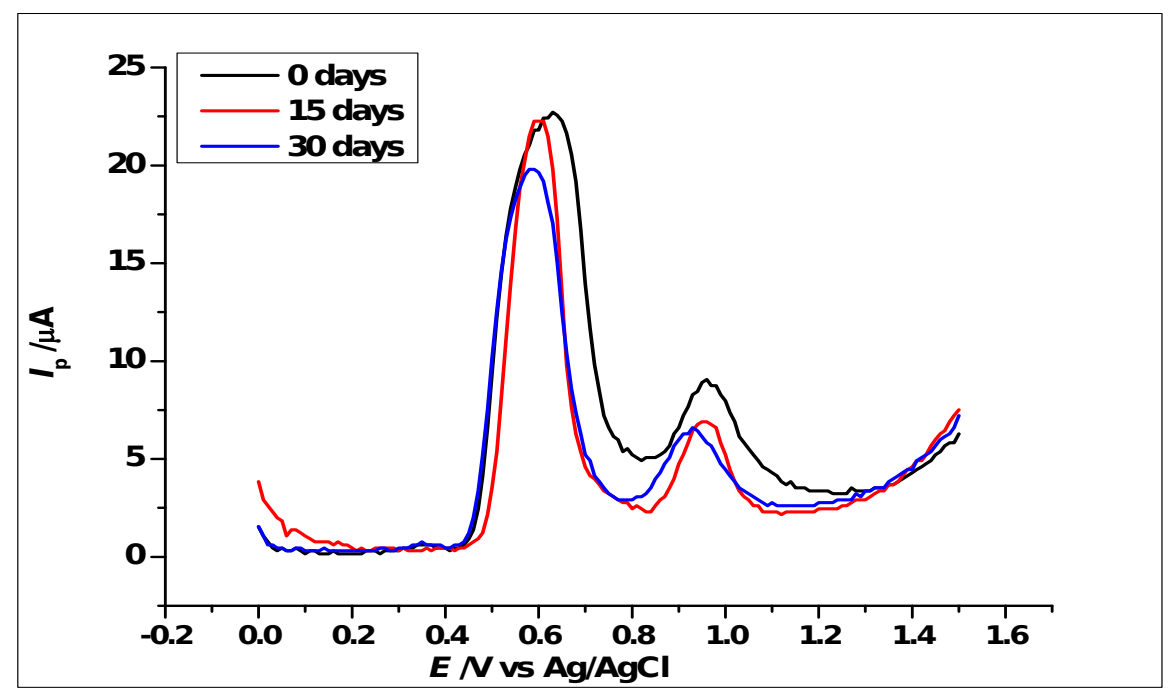

Fig. S10. DPV voltammograms of $5 \times 10^{-4} \mathrm{~mol} \mathrm{~L}^{-1}$ Gallic acid, showing voltammograms measured by the same electrodes after 0 days, 15 days and 30 days: showing stability. 


\section{S11. Interference Study}

Table S2. Effects of various foreign species on the determination of GA $\left(1 \times 10^{-2} \mathrm{~mol} \mathrm{~L}^{-1}\right)$

\begin{tabular}{|l|c|c|c|}
\hline & Interfering Species and Ions & Concentration $\left(\mathbf{m o l ~ L}^{-1}\right)$ & Relative Standard Deviation (\%) \\
\hline 1 & $\mathrm{~K}^{+}$ & $1 \times 10^{-1}$ & \pm 2.54 \\
\hline 2 & $\mathrm{Cl}^{-}$ & $1 \times 10^{-1} .77$ \\
\hline 3 & $\mathrm{Na}^{+}$ & $1 \times 10^{-1}$ & \pm 4.51 \\
\hline 4 & $\mathrm{Fe}^{3+}$ & $1 \times 10^{-1}$ & \pm 0.61 \\
\hline 5 & Ascorbic Acid & $1 \times 10^{-3}$ & \pm 3.7 \\
\hline 6 & Quercetin & $1 \times 10^{-3}$ & \pm 4.16 \\
\hline
\end{tabular}

\section{S12. Voltammograms of GA determination in Wine Samples}
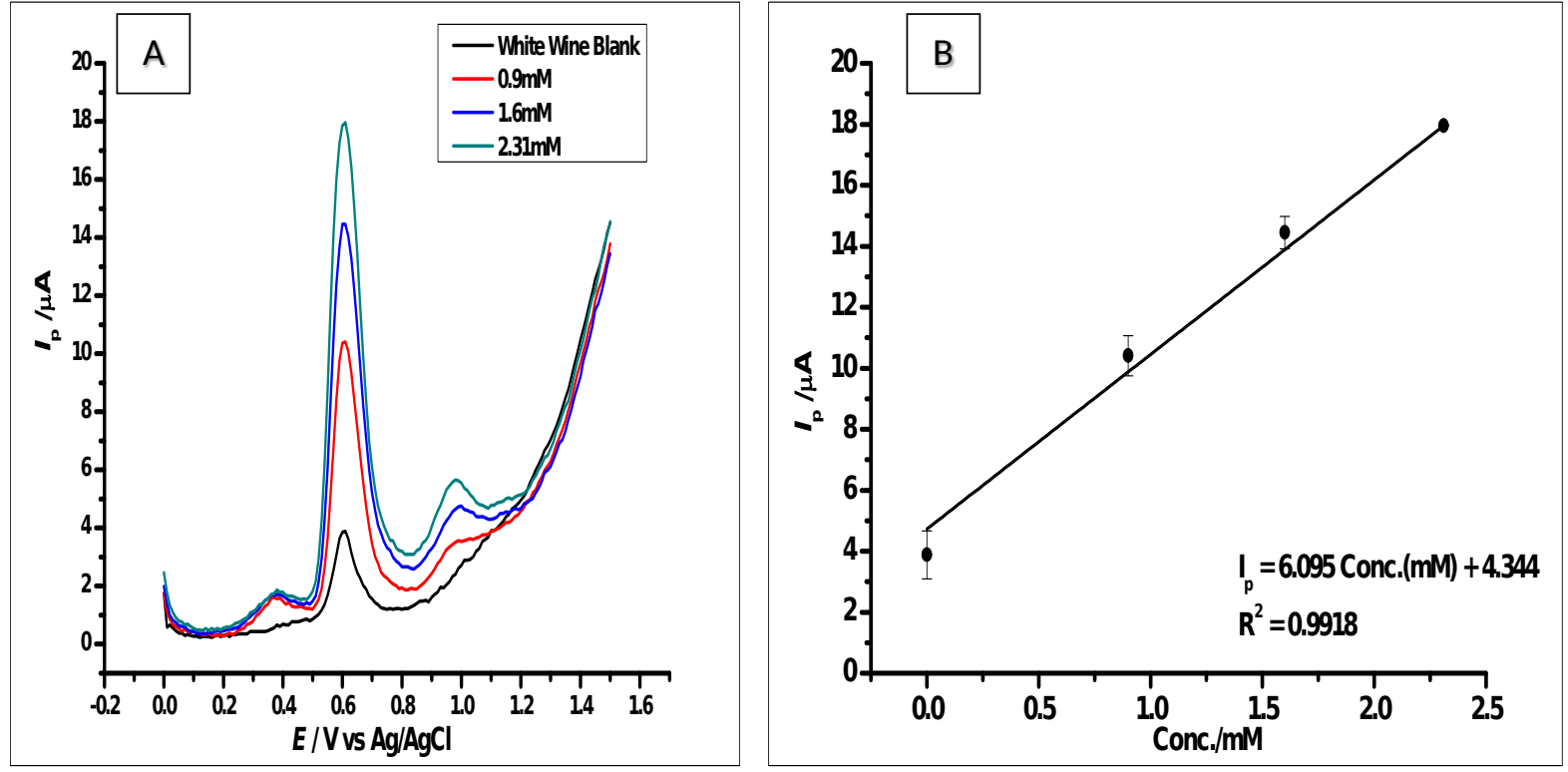

Fig. 12. (a) Voltammograms of aliquots of $1 \times 10^{-2} \mathrm{~mol} \mathrm{~L}^{-1}$ of GA added into White Wine using a standard addition method (b) Calibration curve of the standard addition of Gallic acid. 

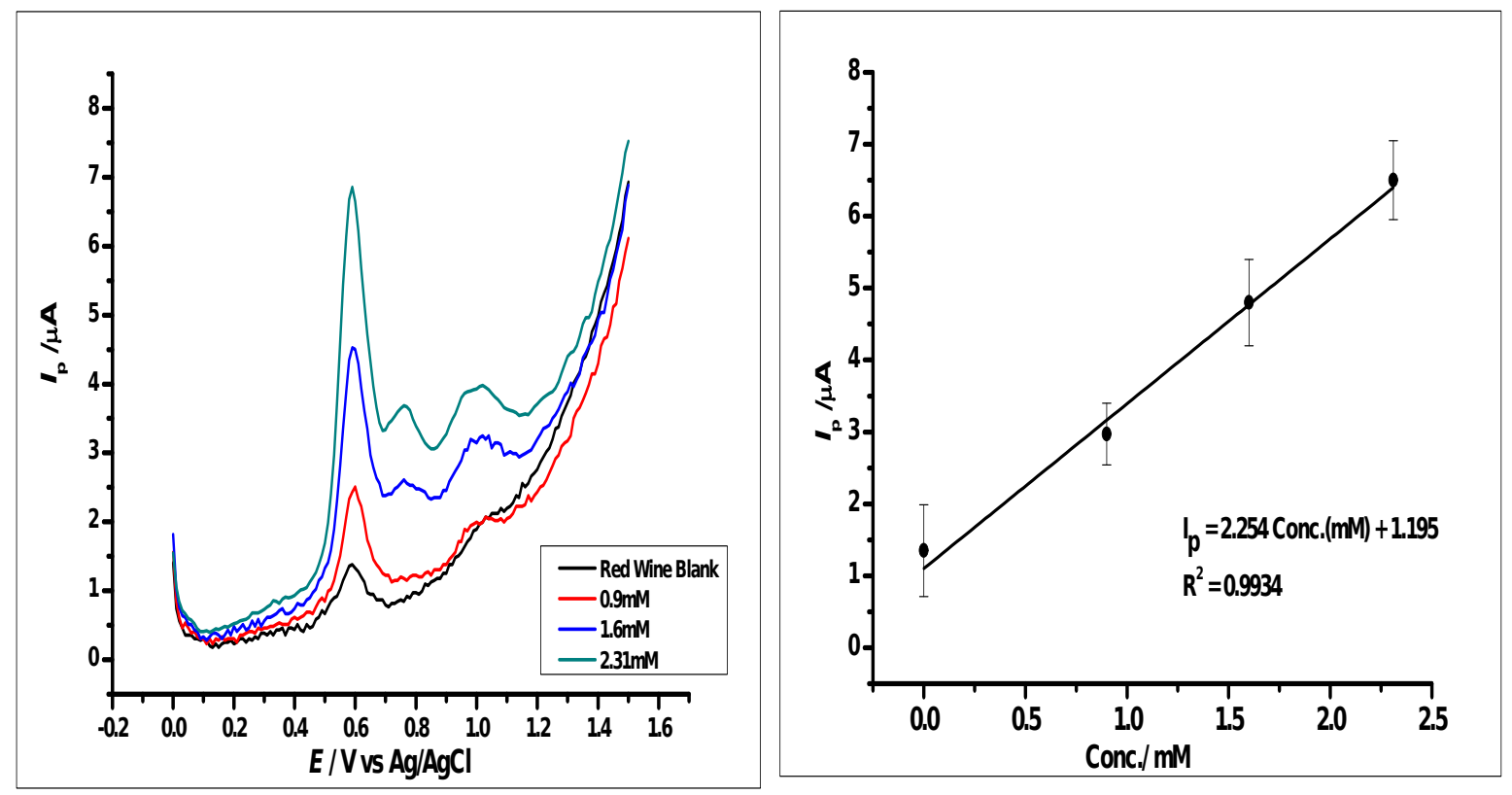

Fig 13. (a) Voltammograms of aliquots of $1 \times 10^{-2} \mathrm{~mol} \mathrm{~L}^{-1}$ of GA added into Red Wine using a standard addition method and the presence of the third peak.

S14. HPLC Analysis of wine samples to validate the presence of GA in the Wines.

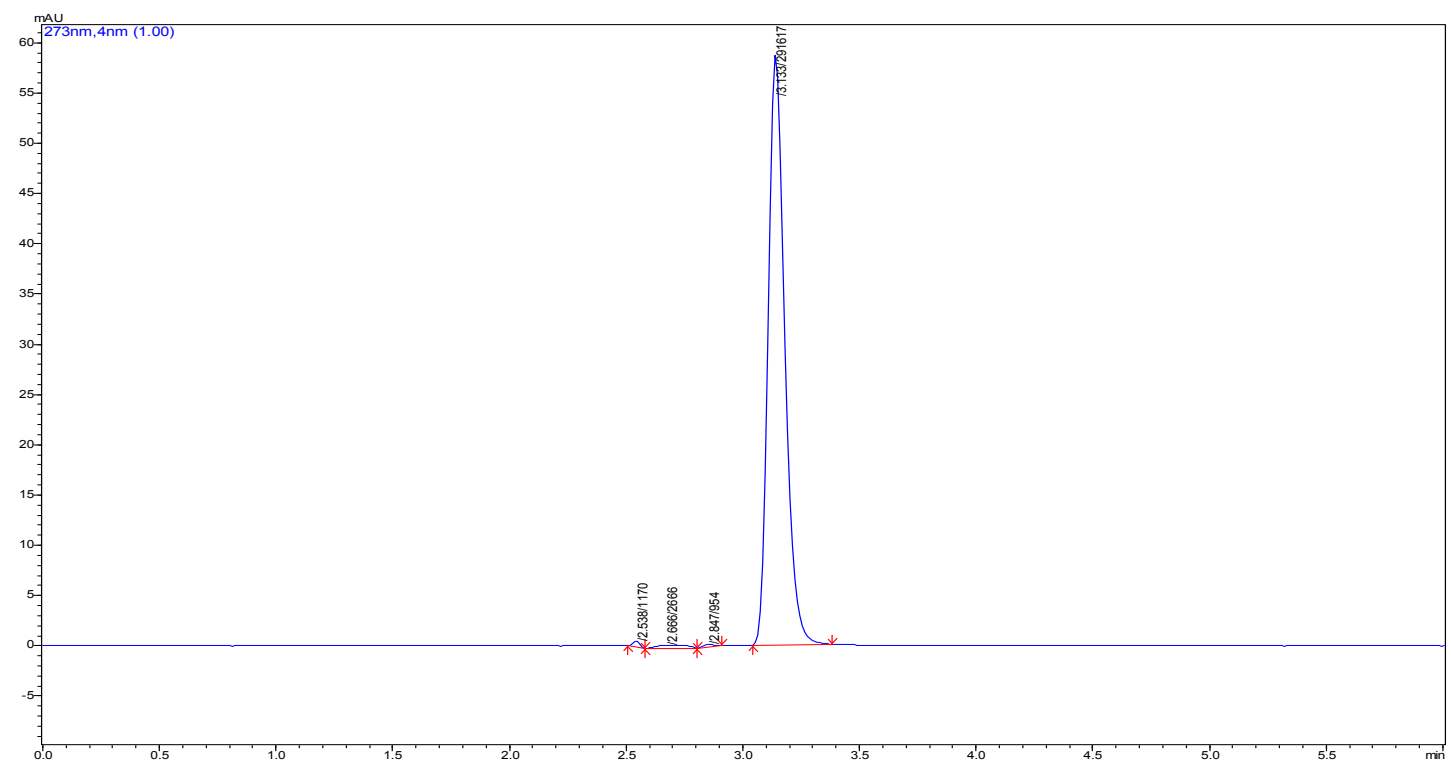

Fig 14. (a) Chromatogram of Gallic acid standard at retention time 3.13 mins. Giving the time Gallic acid would be expected in a Red or White wine. 


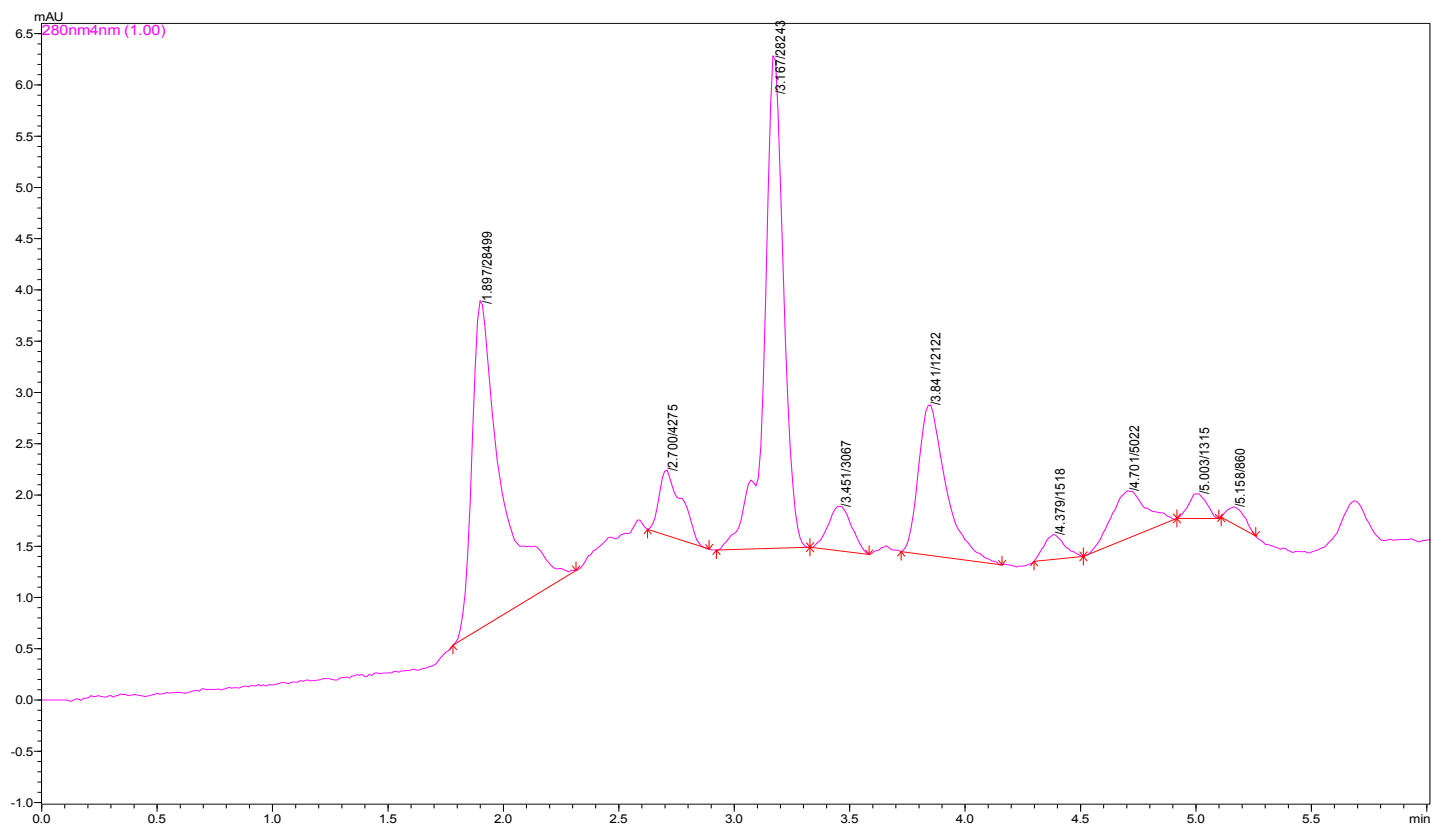

Fig 14. (b) Chromatogram of Red Wine showing the Gallic acid peak at retention 3.16 min.

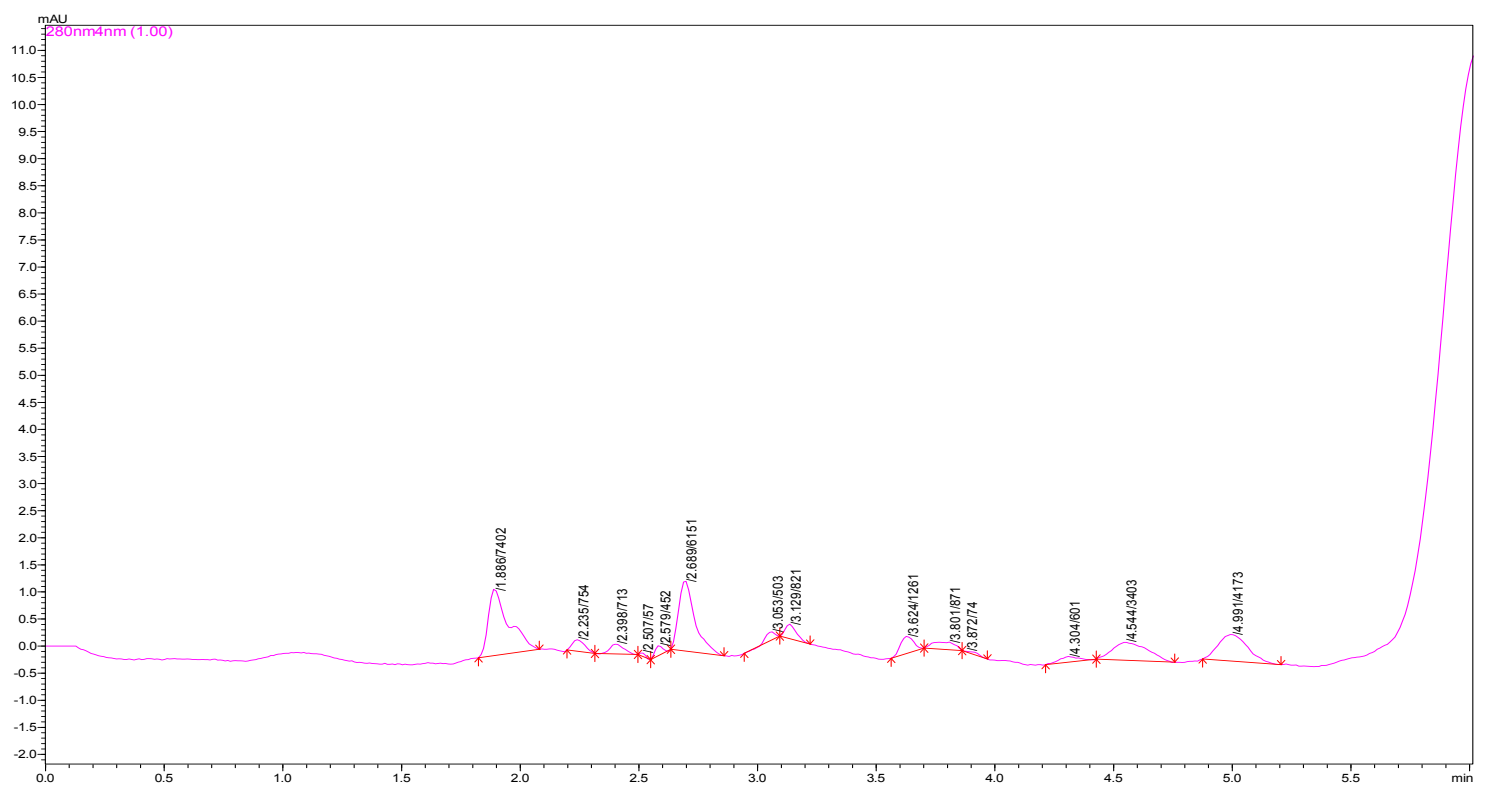

Fig 14. (c) Chromatogram of White Wine showing the Gallic acid peak at the retention time 3.12 min 